Chapman University

Chapman University Digital Commons

English (MA) Theses

Dissertations and Theses

Spring 5-2021

\title{
The Tiered Workshop: The Effects of Using a Paced Workshop in a Composition Classroom
}

\author{
Madison Shockley \\ Chapman University, mshockley@chapman.edu
}

Follow this and additional works at: https://digitalcommons.chapman.edu/english_theses

Part of the Rhetoric and Composition Commons

\section{Recommended Citation \\ Shockley, Madison Jo. The Tiered Workshop: The Effects of Using a Paced Workshop in a Composition Classroom. 2021. Chapman University, MA Thesis. Chapman University Digital Commons, https://doi.org/ $10.36837 /$ chapman.000252}

This Thesis is brought to you for free and open access by the Dissertations and Theses at Chapman University Digital Commons. It has been accepted for inclusion in English (MA) Theses by an authorized administrator of Chapman University Digital Commons. For more information, please contact laughtin@chapman.edu. 


\title{
The Tiered Workshop: The Effects of Using a Paced Workshop in a Composition Classroom
}

\author{
A Thesis by \\ Madison Jo Shockley \\ Chapman University \\ Orange, CA \\ Wilkinson College of Arts, Humanities, and Social Sciences \\ Submitted in partial fulfillment of the requirements for the degree of \\ Master of Arts in English
}

May 2021

Committee in charge:

Morgan Read-Davidson, MA/MFA, Chair

Ian Barnard, Ph.D.

Sarah Robblee, Ph.D. 
The thesis of Madison Jo Shockley is approved.

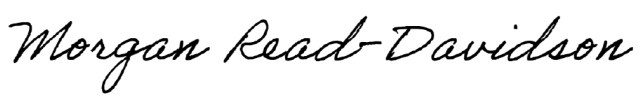

Morgan Read-Davidson, MA/MFA, Chair

Aan Barnard

Ian Barnard, Ph.D.

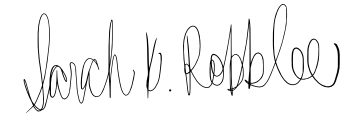

Sarah Robblee, Ph.D.

May 2021 
The Tiered Workshop: The Effects of Using a Paced Workshop in a Composition Classroom

Copyright $\odot 2021$

by Madison Jo Shockley 


\section{ACKNOWLEDGMENTS}

I would first like to acknowledge the members of my committee, Dr. Sarah Robblee and Dr. Ian Barnard, for being so supportive and inspiring me not only to pursue this topic but also to pursue a career in higher education. I express my deepest gratitude for my thesis chair, Morgan Read-Davidson, for working so diligently and patiently with me since Fall 2020. Your guidance and wisdom are unmatched; I would be nowhere without your support and trust.

I would also like to thank my family, friends, and loved ones for the words of encouragement in the many stressful times throughout this year-long process. A sincere thank you to Jacob Johnson for your endless encouragement. I am eternally grateful for your kindness, patience, and support throughout my academic journeys.

Lastly, I would like to thank my English 103: Writing about Environmentalism and English 103: Rhetoric of Environmentalism students from the 2020-2021 school year. Your hard work and determination were immensely inspirational to me as I completed this study. Your passion for writing and unwavering positivity in this hectic time were more valuable than you know. I promise to work continuously and consistently to better my pedagogical practices to better your educational experiences. 


\begin{abstract}
The Tiered Workshop: The Effects of Using a Paced Workshop in a Composition Classroom by Madison Jo Shockley

What are the effects of a paced workshop (defined as a slower writing approach rooted in a scaffolded three-day process working toward a completed rough draft) and how can teachers and students alike benefit from these effects within the scope and situations of a composition classroom and potentially those beyond it? This I.R.B approved study aims to discover how my version of a scaffolded workshop fits into the larger picture of rhetoric and composition and how a paced workshop design can not only offer potential to reframe how scholars structure writing within a composition classroom, but also if it can encourage students' personal growth and writing development as a byproduct. To understand the role that a slower, paced approach toward completing projects has in students' personal and academic lives, I analyzed students' workshop reflections and observed the students in their workshops, which were conducted on Zoom using the breakout room feature. Likewise, interviews were also conducted with willing participants to understand the efficacy of the paced workshop design more clearly. Ultimately, this study explores the opportunities that a paced design welcomes in its slower approach and its potential benefits to students' comfort, personal growth, and writing approaches while easing students' anxieties about their abilities to create as composition students.
\end{abstract}




\title{
TABLE OF CONTENTS
}

$\underline{\text { Page }}$

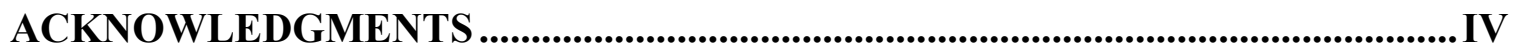

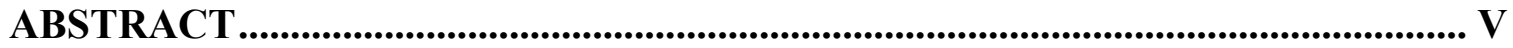

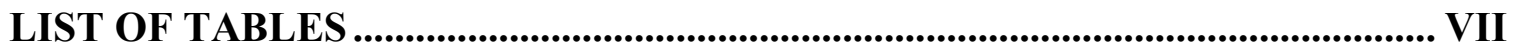

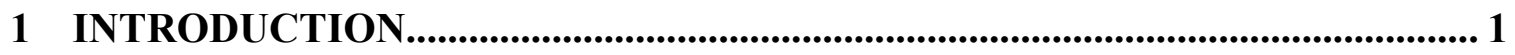

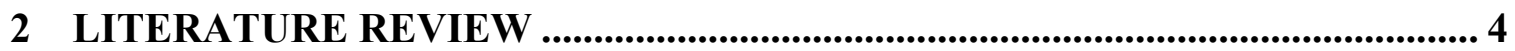

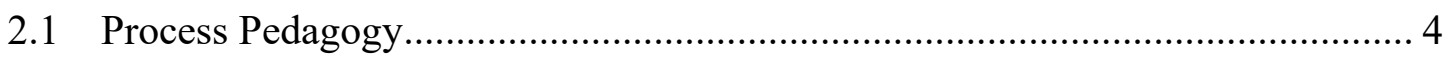

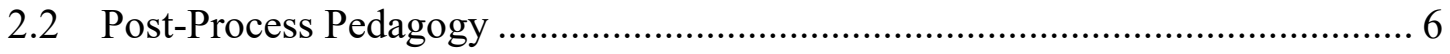

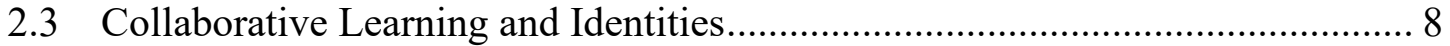

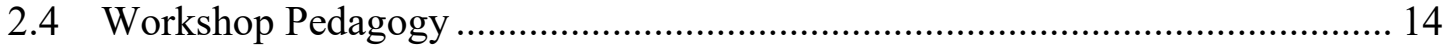

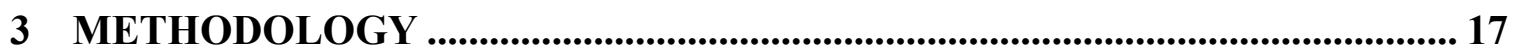

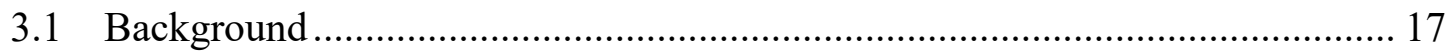

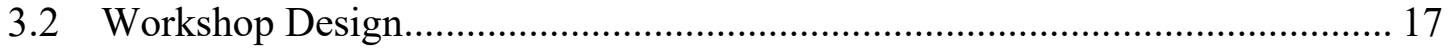

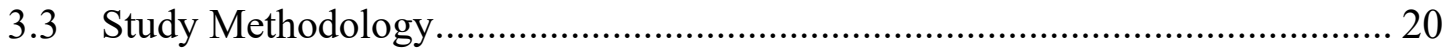

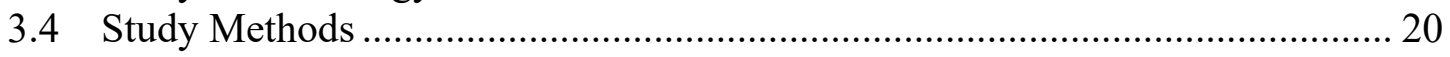

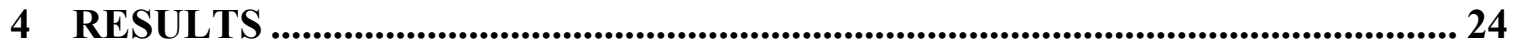

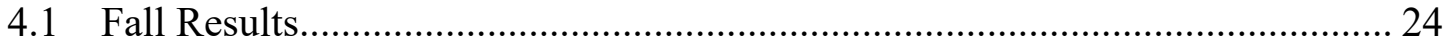

4.1.1 Fall Case Study: Student G ........................................................... 28

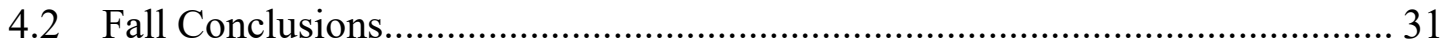

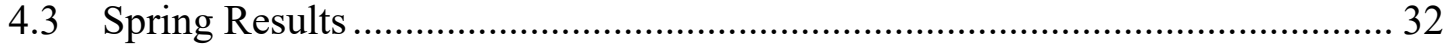

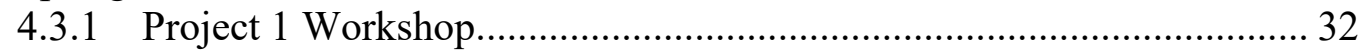

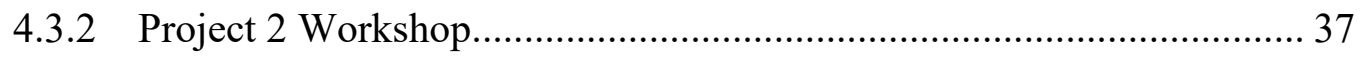

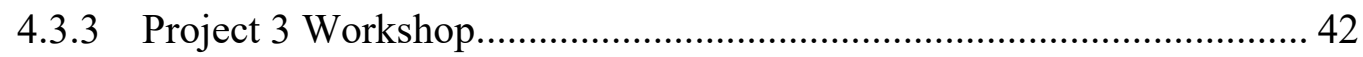

4.3.4 Spring Case Study 1: Student K and Student O................................. 48

4.3.5 Spring Case Study 2: Student N................................................... 52

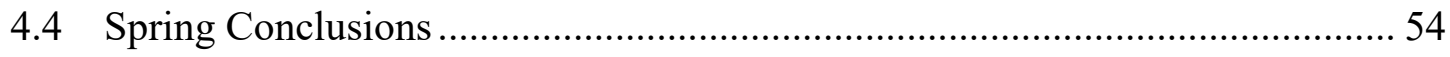

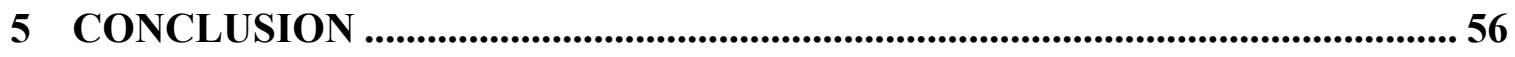

WORKS CITED...................................................................................................................... 58

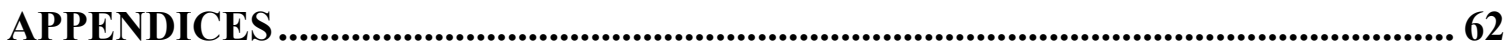




\section{LIST OF TABLES}

Table 1. Project 1 Most Helpful Workshop Day for Feedback .................................... 35

Table 2. Project 1 Most Helpful Workshop Day Material............................................. 36

Table 3. Project 2 Most Helpful Workshop Day for Feedback ..................................... 40

Table 4. Project 2 Most Helpful Workshop Day Material........................................... 41

Table 5. Project 3 Most Helpful Workshop Day for Feedback ................................... 44

Table 6. Project 3 Most Helpful Workshop Day Material............................................ 45 


\section{Introduction}

As I complete my second semester as a Graduate Teaching Associate (GTA), I reflect on how this study originated and how much it has changed over the course of two semesters. When originally designing my course prior to my GTA teaching experience, my decisions were firmly rooted in process pedagogy. Yet, after two semesters of teaching experience, my pedagogical, theoretical, and personal goals have changed as a result of this study.

When designing my course, I used my prior experiences as an impressionable firstgeneration college student to guide my design, especially in my workshop construction. As a first-year student, I was intimidated by what my professor was requiring in my English 103 Freshman Composition course, and out of complete fear and lack of confidence I almost dropped the course. Although the English 103 course I took did not have a continuous workshop, we did have one day of the semester when we swapped drafts of our longest papers with the person next to us and got verbal feedback. While I recall the experience being helpful, I remember feeling apprehensive and nervous about my writing skills and how they would be perceived. Yet, it was this experience I had as a terrified eighteen-year-old that inspired me to consider approaches to writing processes, writing development, and confidence in writing when designing my first-year composition course.

Indeed, this experience was the catalyst for my workshop design in the initial stages of my course, yet it translated to an interest in collaborative learning, writing development, and the role that practice plays in internalizing material and knowledge for composition students. These interests influenced the initial stages of my study, in which I explored process pedagogy (Tobin; 
Lynn) and found results that sparked new interests involving collaborative learning, post-process pedagogy, and identity. Most importantly, my personal experience as a student paired with my teaching experience as a GTA inspired the desire to establish what a potentially "successful" workshop experience would look like.

This study considers "success" to be something that can be self-reported by the students in their reflections and interview and/or observed by myself during the workshop breakout rooms. In this sense, "success" can be an articulation and metacognitive understanding of their abilities, abilities akin to Peter Elbow's process pedagogy in Writing Without Teachers, wherein participants are able to determine the choices they make and their meaning behind them while having an increased sense of comfort and confidence in one's own ability (vii-viii). Evidence of success may be articulated as visible happiness, comfort, less anxiety, etc., but can also be selfreported phrases such as "That makes more sense," "I feel better about these choices," "I'm excited," etc. Yet I recognize that a student may self-report that the workshop is successful for them while there may not be evidence within their writing of this improvement. Likewise, success of the workshop process can be acknowledgment of the process itself allowing for these opportunities of comfort and confidence to flourish. However, I acknowledge that success may appear differently depending upon the participant and may not be confined to the definition outlined above.

After the first semester of my GTA program, I sought to determine what more could be explored in the next phase of my study. I constantly returned to one question: What are the effects of a paced workshop (defined as a slower writing approach rooted in a scaffolded threeday process working toward a completed rough draft; workshop design is described in more detail in the Methodology section) and how can teachers and students alike benefit from these 
effects within the scope and situations of a composition classroom and potentially those beyond it? I understood the necessity of continuing this study in the Spring to best understand how pivotal a workshop design can be for students by basing my results upon multiple participants and across multiple semesters. Thus, I aim to discover how my version of a scaffolded workshop fits into the larger picture of rhetoric and composition and how a paced workshop design can not only offer potential to reframe how scholars structure writing within a composition classroom, but also if it can encourage students' personal growth and writing development as a byproduct. 


\section{Literature Review}

\subsection{Process Pedagogy}

I initially began my study exclusively exploring process pedagogy and I aimed to deconstruct the "traditional" workshop design (peer reviewing one completed rough draft) that I had experienced as an undergraduate. I use the theories and developments of process scholars' work of the past and intend to build upon, expand, and complicate what I learned. Thus, inspired by process pedagogy (Elbow; Bruffee) and expressivist pedagogy (Elbow; Burnham), I designed my course to encourage a process-driven approach that was "anti-establishment, antiauthoritarian, anti-inauthenticity" (Tobin 4). Likewise, I strive to uphold the process movement's value of student interest and personal choices within personal, creative, and multimodal writing projects (Tobin; Lynn).

Prior to the process movement, conventional approaches to writing "emphasized academic writing in standard forms and 'correct' grammar" (Burnham 22). Workshop design was either non-existent—students were writing solely for the professor—or whole-class workshops occurred, wherein "students often find it difficult to sort through the sometimes wildly varying responses from their peers" ("Workshop" 199). Considering the teacher-centered nature of traditional workshop and pedagogy, composition teachers began to break away from conventional methods during the expressivist and process movements. While traditional pedagogical approaches emphasize academic writing and authoritative teaching methods, process pedagogy works to "[challenge] the traditional authority of knowledge" established in the traditional structures of a college classroom through collaborative student learning (Bruffee 649). 
Bruffee emphasized small-group workshops and the powerful role they serve within the composition classroom, noting that putting students into groups does not alter what the students learned, but rather, "[changes] the social context in which they learned it" (Bruffee 638). The small-group dynamic is a concept that John Trimbur further highlights with the history of consensus, which "does not inhibit individuality, as it does for those who fear consensus will lead to conformity. Rather it enables individuals to participate actively and meaningfully in group life. If anything, it is through the social interaction of shared activity that individuals realize their own power to take control of their situation by collaborating with others" (Trimbur 604). Within my approach, I aim to acknowledge the degree to which consensus occurs in workshop settings: I do not encourage the "group think" from a teacher-centered and authoritarian standpoint but, rather, encourage consensus and independence among peers, having the workshop driven by students wherein I am merely an observer. I encourage my students to give constructive, respectful advice, and if others within the workshop setting agree, then that is only enhancing the collaborative actions and energies created. Thus, as Trimbur states, the role of consensus "does not violate the individual but instead can enable individuals to empower each other through social activity" (Trimbur 604) and must be seen "not as an agreement that reconciles differences through an ideal conversation but rather as the desire of humans to live and work together with differences" (Trimbur 615). This recognition of differences among students—-backgrounds, gender, identities, class rank, and writing processes/styles—must be acknowledged and upheld within collaborative activities. Within my workshop design, I value the composition of my workshop groups, keeping these factors in mind. Likewise, I consistently remind my students that one is welcome to disagree, yet they must be respectful and mindful of 
their peers when voicing these matters of disagreement, as I encourage constructive criticism rather than harmful opinions.

Yet, while process pedagogy was undoubtedly influential to the field of rhetoric and composition, there can be pitfalls that accompany upholding process pedagogy within a composition classroom. Most notably within conversations surrounding process pedagogy is the issue with enforcing a linear process, wherein following a prewriting, writing, and revision setup can suggest that the writing process cannot take any other form or approach (Tobin 11). This formulaic pattern is something I deeply considered when creating my workshop design, and while my design includes a brainstorming, predrafting, and rough draft stage, I encourage students to establish recursivity by revisiting or recreating workshop material to assist in their individualized writing process. Likewise, my workshop design works toward establishing that nothing is ever set in stone, that everything completed for our workshop is considered a rough draft until the final week of class when the final portfolio is due. This emphasis is to mimic an invention process as best as possible, encouraging a model that supports Janice Lauer's “criteria of transcendency, flexibility, and generative capacity for judging the effectiveness of a heuristic procedure" (Clark 54) in a scaffolded structure to help eliminate anxieties surrounding working through a writing process. Although the portfolio is the students' end goal of the semester, the process in which this end goal is met is driven by recursivity. Since all materials are treated as rough drafts until the portfolio is due, my underlying goal is to help ease grading anxiety by not having anything rooted in finality until the last week of the semester.

\subsection{Post-Process Pedagogy}

While the initial stages of my study worked to build upon process pedagogy, as I delved deeper into my study, post-process pedagogy and practices began to influence my understanding 
of workshop design and desired goals of this study. For instance, process pedagogy has been critiqued for its "[attempt] to systematize something that simply is not susceptible to systematization... [writing] is radically contingent, radically situational" (Olson 8-9). Within post-process work, scholars such as Timothy Oleksiak, dismiss traditional notions of peer review centered on "seductive" promises of improvement. Oleksiak advocates for a "slow peer review" that is in conjunction with queer theory and rhetorical listening that "liberates [instructors] and our students from having to perfect these texts" (Oleksiak 327) while "[honoring] unimproved writing" in that "the queerness of slow peer review is in its demand for more space... [it] is not simply a moment, but a series of moments that come to be known over time as queer praxis" (Oleksiak 328). Oleksiak's process has students read their partner's draft five times, with each phase of the workshop building on the next, aiming to emphasize the words and writing through reading several times before any comments or revisions are made, which occur in the latter half of the process (Oleksiak 320). This slow approach helps students recognize the role that the writing itself serves and what consequences may arise from it. Specifically, slow peer review aims to validate students' voices, their word choices, and their role within the world in which they write for and enact. By focusing on the ability for students to make meaning, connections, and realizations about their peers' writing, Oleksiak suggests that the purpose of writing within a slow peer review format functions as "the ethical negotiation of textual worldmaking activities" (Oleksiak 329) rather than utilize peer review in the classroom as a means of improvement. Likewise, Oleksiak's structure of slow peer review is reliant upon a scaffolded systemization designed for attentive listening and situational awareness, working to complicate the notions that writing is restricted to the classroom as well as peer review is designed for the improvement of writing. As I similarly emphasize within my workshop design, the workshop pacing is intended 
to ease the anxieties attributed with writing, taking a slower approach to ease the student into the writing process rather than jumping into the project head-on. It is my intention to emphasize the students' capabilities within this process, encouraging them to recognize the larger role that pacing has on their abilities, confidence, and writing approaches.

Furthermore, I aim to evaluate a paced workshop design on the efficacy of whether having a recursive approach toward seemingly "linear" stabilities and systems allows for written and personal student development. Given most students in a composition classroom are first-year students, it is crucial to maintain throughout the semester that this design is fluid and upholding an opportunity to enforce "collective explanations" rather than a herd community way of thinking, validating students' voices and differences that may arise during a workshop. Likewise, it must be recognized that this paced design does not aim to negate nor undermine post-process pedagogical attempts to de-systemize writing in a college classroom. Instead, I aim to acknowledge the "social epistemic" approach to writing while upholding post-composition techniques, creating a system that can "be functional, effective, and perhaps efficient over time in order to extend its movement in other directions" (Dobrin 145). This post-process approach toward a process-based workshop provides an opportunity for understanding how student writing processes can extend beyond the linearity of the structure itself, working to acknowledge that writing can be situational but also rooted in recursivity to encourage internalized practice.

\subsection{Collaborative Learning and Identities}

Collaborative learning proved vital to ensuring this study was successful. Given the extensive scholarship on the subject, I was inspired to implement many of these strategies and pedagogical approaches within my workshop design. Collaborative learning has been praised for its ability to "decenter the classroom, opening it up to difference and dissent" while providing an 
opportunity for students to "teach each other... [and] discover things that individually they might not... [while being] more involved than they are in the potentially passive whole-class context" (Howard 59). Likewise, collaboration not only provides agency to students but also works to improve students' work in the process, "[harnessing] the powerful educative force of peer influence that had been-and largely still is-ignored and hence wasted by traditional forms of education" (Bruffee 638).

Indeed, collaborative learning works to defy the stereotypical "solitary author," wherein "purposes, like ideas, arise out of interaction, and individual purposes are modified by the larger purposes of groups... when it is recognized as such by others" (Cooper 369). This ecological model approach encourages a dichotomy of writing as a social act (Cooper; Roozen) in a dynamic fashion. Similarly, returning to Dobrin's post-compositional approach, an ordered system can be dynamic and cohesive while meeting "ends that seem, at first, counterproductive but that, in fact, serve the longevity of the system" (Dobrin 146). By having an "ordered system" structure of workshop rather than practicing process as a linear process, an "ordered system" can allow for the simultaneous social act of writing when based within group interaction. Although the days are "given" in terms of workshop, the work the students produce is entirely of their own interest and is expected to evolve and grow throughout the process of workshop, encouraging an opportunity for writing to transcend beyond the act itself in a flexible order and highlighting the "longevity" of writing development over time.

In the same vein as collaborative learning, David Williams Shaffer cites Lave and Wenger's community of practice, defining it as a group that "share[s] a repertoire of knowledge about and ways of addressing similar (often shared) problems and purposes... [and have a] common body of knowledge and set of skills but also a system of values that determines when 
and how those skills and that knowledge should be employed and a set of processes through which such decisions are made" (410). The goal of my workshop design is to help my students become a part of a community of practice, instilling an opportunity to share and address various forms of knowledge while creating meaningful relationships in the process. Yet, like any new discourse that students are entering, a discussion of writing can be overwhelming for students in a variety of ways: feeling apprehension about sharing their ideas, experiencing an "imposter syndrome", and dealing with social anxieties. The ability for students to act within this practice as well as articulate this practice can become troublesome. This articulation of practice invokes David Bartholomae's approach toward discourse, wherein students must "invent the university by assembling and mimicking its language while finding some compromise" (Bartholomae 590). This mimicry of writing, language, and articulation of the distinct discourse replicated within the community of academia creates problems with authenticity and identity. To resolve these issues, Bartholomae suggests students better understand and articulate their knowledge by “" [building] bridges' between their point of view and the reader's" (Bartholomae 594). Since students may not be able to "speak to us in our terms - in the privileged language of the university discourse" (Bartholomae 593), they can begin to formulate their own terms, articulation, and understandings within collaborative acts. This harkens back to Bruffee's collaborative learning pedagogy and "normal discourse" of the universities. Bruffee suggests that when students work together to discuss their writing they focus less on improving the text itself and more so on conversing about the writing in their own understandings of the "normal discourse": "They converse about their own relationship and, in general, about relationships in an academic or intellectual context between students and teachers... They converse about and as a part of understanding. In short, they learn, by practicing it in this orderly way, the normal discourse of the academic community" 
(Bruffee 645). Ultimately, this articulation of discourse is beneficial not only in the practice of collaboration but also in the articulation of this practice; students can work toward an epistemic rhetoric by speaking in their own modified discourse, increasing their agency in the process.

Likewise, Shaffer's community of practice continues this notion of re-articulation and collaboration, wherein students trust themselves and their peers when being challenged by discussing writing, encouraging students to simultaneously learn to collaborate and articulate the challenge itself. Likewise, this concept of community of practice is akin to Bruffee's collaborative learning theories. When a community of practice is in place, students can perceive "that writing is not an inherently private act but is a displaced social act we perform in private for the sake of convenience" (Bruffee 745). Creating space in the college classroom for the acknowledgement and validation of a community to practice skills, opinions, and differences works to defy the solitary author further, reiterating that writing is a social act.

With extensive peer collaboration, identity becomes a factor to consider both in terms of the individualized self and the establishment of a communal identity. Yet rather than emphasize writing as an "act of encoding or inscribing ideas in written form" (Roozen 50), writing instead acts "as a means of engaging with the possibilities for self-hood available in a given community" (Roozen 51). Considering this notion of identity, when collaborative learning works to defy the solitary author, students avoid an "internalization" of writing approaches and characteristics subjected only to oneself (Cooper 371). Instead, students can develop an identity within a community, learning to "[develop] habits and skills involved in finding readers and making use of their responses" (372).

The concept of communal identity is relevant to Shaffer's epistemic frame, where there is "the combination—-linked and interrelated — of values, knowledge, skills, epistemology, and 
identity' that people have as part of a particular community of practice" (411). Within a community of practice, the development of individual identity through exploration of specific context in situated activities is potentially viable. Yet there can also be a development of communal identities, given the shared values and skills within this community being exchanged. Especially during the COVID-19 pandemic and the resulting wave of online learning, establishing bonds and relationships was something I prioritized; I encouraged students to talk amongst themselves once workshops were completed to help establish a sense of community among the students, especially considering the workshop was taking place on the rather distancing platform, Zoom, in the midst of a pandemic.

Yet simply because peers can become a part of a community of practice, there must be acknowledgement that students may have differing backgrounds that do not interrelate. As Christine Martorana suggests, a "figured worlds" (Martorana 60) approach to collaboration is the most productive and effective collaborative learning model given its emphasis on social and cultural backgrounds can "evoke a more explicit attention to the power dynamics that undergird all collaborative acts" (Martorana 60-61). Connecting with the concepts of power and collaborative learning outlined earlier with Trimbur, Martorana's approach ensures that sociocultural dynamics are recognized within the collaborative space. Ultimately, this "figured world" of the university harkens back to Bartholomae, wherein the sociocultural power dynamics may affect the discourses that arise in collaborative learning. Thus, I want to reiterate that the composition of my groups is intended to allow space for rhetorical listening and the decentering of predominantly white, male privilege within the college classroom. Likewise, I hope that the opportunities of meeting with all students in the classroom allows for rhetorical listening and 
sociocultural aspects to come to light within the workshopping space, something that Oleksiak also considers within the slow peer review design:

Rhetorical listening attempts to help white folks understand that they have been using the dominant voice and that they are represented to an unequitable degree in issues of race.... Queer rhetorical listening expands what we attune to during moments of cross-cultural rhetorical negotiation. A powerful moment of cross-cultural contact that carries the weight of multiple identifications is peer review. Slow peer review makes use of queer rhetorical listening during these moments (Oleksiak 319).

By encouraging my students to first read their peers' work and offer comments prior to workshop, the time spent within the breakout room encourages the students to practice modes of rhetorical listening. When in their groups, opportunities for "cross-cultural contact" with students of color and womxn students is something necessary when at an institution wherein white, male students tend to be favored and potentially dominate in class discussions. While the majority of both courses had white students, my workshop groups during the second semester intended to have the white students dispersed among the groups, with students of color and womxn composing the majority of the groups, in order to encourage rhetorical listening for the white and white male students. Likewise, I compose the groups of two to three students per group, and students switch groups and meet with new partners for each project. By the end of the semester, they will have worked with at least half of the students in the class. My intent with the composition of my workshop groups is to help the white students practice rhetorical listening and respectful discourse within the classroom, wherein the design of the groups can encourage a recognition and validation of difference within the collaborative space for the students of color and womxn. While collaborative learning offers a space for peer relationships to become 
established, this sense of community must consider the range of individual identities and backgrounds, and how these are applicable within the community. Thus, prior to composing my workshop groups, I allow for several group activities to take place in the classroom as well as assign personal prompts for students to answer - such as an introduction video on the first week of class and freewriting prompts - to gain a sense of who they are as individuals.

\subsection{Workshop Pedagogy}

Early in my preparation as a GTA, I read Anne Lamott's "Shitty First Drafts," which not only encouraged my workshop design but also acted as my first introduction to workshop pedagogy. Lamott's approach to drafting is based upon "terrible first efforts," wherein freewriting takes place, completing what she calls "the down draft"; then, students create the "up draft...[and] try to say what you have to say more accurately. And the third draft is the dental draft, where you check every tooth, to see if it's loose or cramped or decayed, or even, God help us, healthy" (Lamott 2). Lamott's emphasis on imperfect, yet scaffolded, writing was pivotal to my pedagogy, acting as the catalyst for understanding whether this approach to writing was beneficial to students as much as it was for Lamott. I embodied Lamott's principles in my workshop design, reiterating that their writing is consistently in a "rough draft stage" until the final week of class, hoping to ease anxieties of students having to figure out what qualifies "perfect" or "finalized" writing by allowing time for students to explore this with care.

Considering writing approach and development, Howard Tinberg asserts that metacognition "requires that writers think about their mental processes... [and] allows writers to assess which skill and knowledge sets apply in these novel situations and which do not" (Tinberg 76). Tinberg states metacognition can encourage "an awareness of how that performance came to be" (Tinberg 75), considering on a deeper level, helping the students not only understand what 
choices they made but also how these choices affect their writing. By assigning a metacognitive reflection after each workshop, I hope to provide a deeper understanding of students' writing processes and rhetorical techniques and, most importantly, allow for a space of reflection on how workshop has affected them beyond the scope of learning material. I hope that pairing metacognition with a scaffolded workshop design allows students to reflect on who they are, how they grow and evolve over the course of the semester, and how they recognize and articulate this growth themselves.

With workshop pedagogy, writing center theory and pedagogy fall hand in hand when it comes to collaborative learning. As Muriel Harris discusses, collaborative learning and collaborative writing are two different areas of focus each with their limitations and consequences; yet, peer reviewers emphasize informing students of suggestions or advice they should consider whereas tutors assist in leading the student toward their own discovery of what to change (Harris 377). Likewise, Harris states peer review groups can entice "joint authorship," enacting a space for "real-world writing is often collaborative writing" that is often absent in tutoring sessions, thus "peer-response groups are also closer to what writers may find themselves doing in their jobs" (Harris 377). This concept of situational writing is reminiscent of postprocess theory mentioned earlier; however, my workshop design encourages students to take on a tutor role, offering suggestions and advice while assisting their peer review partner toward discovering opportunities for change themselves, while establishing a comfortable and casual environment in the process. The goal of my workshop is not for students to leave the workshop strictly with an understanding of writing and what the next steps for development are, but also leave with a stronger sense of confidence and individuality that has been uplifted by the workshop process and their peers within the workshop session. 
Therefore, as I desired to determine the efficacy of a paced workshop on student growth and confidence when collaborative learning theories were in conjunction with process- and postprocess applications, then my next question was: Is it actually happening? 


\section{Methodology}

\subsection{Background}

This IRB-approved study was conducted across the span of two semesters using my Fall 2020 English 103 Writing about Environmentalism course and Spring 2021 English 103 Rhetoric of Environmentalism course at Chapman University. The students in both courses completed three projects: a multimodal project in which they visually represented environmentalist visual rhetoric; an interview project in which they interview a subject to understand the subject's deeper connections and relationships to the environment; and a research proposal in which students research an environmental issue of their choice and propose a solution. I made slight adjustments to the projects between the two semesters in terms of audience, publications, and word count. These changes were minimal and meant to offer more clarity to the projects; the prompts did not change. I offered a more specific understanding of audience and publication to help root the project in stronger rhetorical approaches while the word count change was a slight decrease in word count for Project 3. Each project was workshopped for three class periods (once a week across the span of three weeks), and students submitted a portfolio of two of three revised projects at the end of the semester. The final portfolio includes their two revised final drafts and a reflection that focused on the projects, their growth as a writer and rhetorician, and the course.

\subsection{Workshop Design}

My workshop design was based on both my personal experiences as an undergraduate student, and on previous scholarship regarding the writing process and collaborative learning 
pedagogy. The first day of workshop is an "Idea Document," building off of Jody Shipka's "project notes" (Shipka 225), where students submit a page of ideas, approaches, brainstorming, and questions about the project. Taking Shipka's "project notes" to a deeper extent, the second day of workshop is a "Detailed Outline," where students submit a detailed explanation and approach of their chosen idea for their project. For the final day of workshop, students submit a "Rough Draft 1," a partially completed draft of their project that meets at least half of the word count of the final project requirements as detailed on the syllabus. Having students submit a partially completed draft rather than a final draft was influenced by Doug Downs's approach toward revision (Downs 66), not only encouraging students to ease their anxieties about a "perfect" draft in one week but also allowing an opportunity for students to discover areas to expand upon, improve upon, or reconsider based on peer feedback. Likewise, a partially completed draft encourages student "externalization" (Bazerman and Tinberg 61) of their work, encouraging students to recognize the reality that writing is influenced by readers as well as inherently “expressionistic — revealing primarily writers' thoughts and emotions" (Bazerman and Tinberg 62). While the aforementioned workshop materials all receive strictly peer feedback, following the submission of "Rough Draft 1," they submit "Rough Draft 2"—an "imperfect" draft that meets the requirements—one week later that receives my feedback. Building off of Tinberg's “Talk Back" method (Tinberg 249-250), I encourage my students to respond to my comments freely and openly on Canvas, promoting a fluid dialogue rather than an authoritative order to follow my suggestions. Likewise, I refer to questions/concerns/statements for their peers as "discourse generators" for this same reason: to help students understand that the discussions in workshop are a conversation rather than a debate, to simultaneously ease some anxieties of 
creating the "perfect" questions as well as reiterate that anything can be a mode of conversation, not just a question that one's peer answers and is automatically taken as correct.

It is through this workshop design that I aim to explore the effectiveness of how students approach writing through a consistent, revision-based lens. Do students find it helpful to have a paced workshop? Do they ultimately feel more confident and comfortable with writing in comparison to the beginning of the semester? The effectiveness of workshop is measured using the rubrics outlined in Appendix B, the workshop reflections, one-on-one interviews, and workshop observations. More specifically, it is gauged using self-reported or observed statements by the participants that expressed that writing is easier for them. This may or may not include what specifically from our workshop process can be taken into other writing situations, no longer finding writing challenging, learning about themselves/their writing/writing approaches from working with their peers, being able to articulate the effectiveness of the paced workshops in their own words, and feeling more confident in approaching writing in future situations. Within observations, this can be a progressive ease in discussing their writing, comfortable body language or tone, prompting further questions about their writing, etc. The intent in understanding the confidence of the students in conjunction with their writing is not to determine that their confidence equates better writing. Harkening back to Oleksiak, the goal of my workshop design is to avoid the "improvement imperative" (Oleksiak 307) and instead ease students' anxieties surrounding writing, in turn making them more confident in the writing process rather than the final product of writing. Thus, the definitions described above are important indicators of the effectiveness of peer review and collaborative learning, as they emphasize the students' experiences and journey throughout this process rather than prioritize the end results. My intent is to make students feel confident in who they are as writers as a result 
of this workshop design, namely in understanding that writing does not need to be perfect nor completed in one sitting; writing that is paced and in rough draft stages is equally as successful and important as the final product.

This study aims to explore how effective a paced workshop is in regard to student written and personal development, recognizing how and if students internalizing the stages of writing through consistent practice produces a better articulation of their writing development and confidence. Thus, as outlined in the rubrics (see Appendix B) and below within my coding processes, their articulation of the writing process can be expressed in a multitude of ways, indicating through various phrases, observations, or actions that internalization of practice has occurred and renders a paced workshop effective.

\subsection{Study Methodology}

The methodological approach that drives this study forward is primarily rooted in grounded theory. This study relies upon qualitative data, using observations, interviews, and existing coursework to determine the results. Grounded theory was crucial to the formation of this study given the importance of receiving results through natural, student-oriented feedback. The workshop reflections were prescriptive in the sense that the participants had a series of questions to respond to in long-form answers. By using these types of qualitative data, the study properly represents the students' experiences during and accounts of the paced workshops.

\subsection{Study Methods}

The methods for this study are rooted in naturalistic observation and discourse analysis of coursework, such as: 
I. Workshop Observations: I conducted workshop observations via Zoom, joining the breakout room with my microphone and camera off. I observed and took notes on student interaction, engagement, explanation, and confidence. I also took notes on how the recipient of the feedback would respond, and how discourse would flow between the two to three partners (was it methodical, natural, etc.).

II. Interviews: I conducted follow-up interviews of participants from the Fall semester willing to be interviewed. I asked about their personal experiences with the workshop, what they believe the overall effectiveness of the pace was, and what they learned about themselves as a writer. I asked the same questions to the students who participated in the Spring semester who were willing to be interviewed. All interviews were in April.

III. Existing Coursework: I assigned three post-workshop reflections and one collective workshop reflection. These were completed through the Canvas discussion board tool and had a series of nine questions that were long form answers. While other aspects of existing coursework are considered and analyzed, such as any workshop materials, the primary emphasis will be placed on their workshop reflections.

The results for this study were determined using an "open coding" method, wherein I searched for specific or related definitions of the qualitative data that was collected throughout the semester. For a timeline of the study and coding process, see Appendix A.

As previously mentioned, the primary effort of this study is to analyze the efficacy of a paced workshop design through self-reported data in writing assignments and/or observed workshop sessions. Within workshop sessions, I observed how comfortable or anxious students were during the Zoom session: Were students visibly anxious to show their work and speak to their peers? Did students seem neutral and calm? Likewise, the discussion of feedback is pivotal 
to determining the naturalistic environment and comfortability of the students during the session:

Did the students seem to list their feedback or make it more of a dialogue? Was the feedback constructive and valuable? Did the students explicitly state that it was helpful and/or make physical cues (nodding, writing notes, attentively listening, etc.) that it was valuable? Did the student explicitly state that the feedback was helpful? Did the student respond with more questions or concerns or did they largely remain silent after receiving feedback? How long did it take for students to begin discussing other materials or matters?

Indeed, determining the efficacy relies on understanding the personal and written growth a student experiences throughout this workshop experience. While growth varies depending on the participant, a general definition of growth in this study is an increased feeling of satisfaction with writing. All participants expressed early in the semester that writing was difficult for them; thus, an indicator of increased growth would be the either self-reported and/or observed comfort and confidence in approaching writing and/or within workshop meetings. Likewise, growth relies on collaborative learning, considering Rebecca Moore Howard's acknowledgement that students learn from their peers given the eliminated "teacher-student hierarchy" that is established through peer workshops, and in turn, "students' empowerment becomes explicit" (57). Growth is not only something that can be self-reported — such as phrases like "The workshops helped me to better understand what was required," "My writing has improved since the start of the semester," etc.- - but also can be something that is gained collectively and collaboratively. Thus, growth and engagement go hand in hand, wherein active engagement builds upon collaborative learning theory, suggesting peer collaboration not only bolsters students' writing skills but also their confidence in the process (Bruffee; Howard; Harris). Building on collaborative learning theory, physical representation of engagement during 
workshop can be tangible — such as visible participation and awareness during workshop—or otherwise — such as responding to and working through peer feedback, offering suggestions and/or help for their peers, offering words of encouragement, etc. With collaboration and communities of practice in mind, positive reinforcement from peers- such as "I really liked your idea," "You did a great job," "I'm really excited to see your project," and variations of gratitude and thanks - also can be considered to determine the effectiveness of workshop. My desired goal of this study would be that, after eleven weeks of workshop, my students gain the confidence, self-assurance, and agency to trust their writing and feel comfortable sharing their writing with peers not only within this English 103 course but to other courses, and potentially beyond academia, as well. 


\section{Results}

This study gathered its results from 15 participants across two semesters of the 2020/2021 school year. It is important for me to acknowledge that this study was presented with challenges and limitations, namely with COVID-19 and looming Zoom fatigue placed on students. Ultimately, I hope to learn from the results gathered from my study and apply them to my future pedagogical and teaching practices, as these results are meaningful, important, and indicative of the power that collaborative learning as a whole offers to the classroom dynamic. Below I summarize, briefly analyze, and offer conclusions on the Fall results, giving directions to the case studies outlined in the Appendix. I provide case studies with analysis based on the interviews I conducted for both semesters. Then, I end this section with the Spring results and conclusions.

\subsection{Fall Results}

In the Fall 2020 semester, I conducted the first phase of this study with seven participants from my English 103 Writing about Environmentalism course. For full analysis of the Fall results, see Appendix D; outlined below are summaries of the results in the appendix.

As a whole, the first phase of the study illuminated the need for a deeper emphasis on student identity beyond the participant's identity as a student (see Case Study 3 in Appendix D). I had hoped students would explore their identities and backgrounds freely, and while some participants did explore their identities as women, most students related this to who they are as students, whether this be academic background, geographical location, or educational histories. Perhaps this was due to the lack of specificity in the assignments themselves, yet, during 
workshop, students seemed to explore their student identities further, connecting with their peers about their majors, registering for classes, and student experiences. While I had initially hoped for more depth, I was happy to see students exploring who they are with others, choosing a topic they can all relate with and contribute to the conversation.

Collectively, the participants were able to establish a communal identity despite the distanced nature of Zoom as indicated in my observations of workshop: students created bonds and friendships during workshop, welcoming casual conversation as students began to share information with their partners about their majors, writing choices, inspirations behind the projects, and struggles with COVID-19 and otherwise. Student D stated: "The workshops helped me because I was able to talk through some of my ideas with another person. It was helpful to both hear from another perspective and better walk through my own thoughts." Student D's reflection response indicates an articulation of practice, wherein Student D reflects on the bonds that were created with peers while simultaneously helping the student with their writing. For more results from the Fall phase in regard to collaborative learning, visit the Collective Analysis: Workshop section of Appendix D.

The self-reported data from the participants in the Fall semester indicated that the Detailed Outline was the most helpful for the participants to plan out their own project and to receive feedback on out of the three workshop materials (also see Collective Analysis: Workshop in Appendix D). In the interviews conducted with participants during the Fall semester, I asked the three students who agreed to be interviewed why they favored the Detailed Outline. When interviewing Student F, she stated the Detailed Outline was most helpful for her because "it went into more depth with organization and specifics," allowing her to "know exactly what potential problems [she] would have" and "it was easy to give pinpointed feedback because of the 
organization [of the workshop]," whereas peer reviewing an entire paper is more overwhelming to her. Student $\mathrm{F}$ also stated she preferred the Detailed Outline as she used it like a living document: when in workshop, she would add directly to the document as her peers spoke and later, when completing the Rough Draft 1, she would modify it as needed. Student F's articulation of language in regard to the workshop ("pinpointed," "exactly," "into more depth") evokes Bruffee's discourse pedagogies, with Student F being able to epistemically articulate this practice and its usefulness, which I found impressive and valuable given the interview took place nearly four months after the semester's end. Similarly, Student G found the Detailed Outline most helpful because "the hardest part about writing is starting it," wherein the Detailed Outline allowed her to "not avoid it [or] procrastinate... the pace gave us more processing time." Student G's ability to definitively state that the paced design helped her to avoid these concerns and by referring to the design in regard to "processing time" emphasized that the paced design encouraged her to comfortably "cruise" through the documents - invoking Oleksiak's slow peer review here — and give her an opportunity to start rather than push it away.

All three students mentioned how valuable the pace design was to them: Student $\mathrm{F}$ "misses this pace" and expressed desire for her other classes to section out writing assignments, but she learned from the pacing that "it's okay to have ideas fizzle out and know that ideas are not perfect," which she shared makes her feel "more confident with [her] ideas"; Student C discussed how she often "needs a lot of validation" when it comes to writing and her ideas, and the workshop "definitely contributed to that," helping her to "progressing into ideas more slowly and help [her] think more deeply now rather than jumping into a paper and having to restart because I didn't like what I wrote, like I used to do before your class"; Student G stated the paced design helped ease her anxieties as a fourth-year student taking five classes, wherein 
"although there were many assignments, each were built on the next one," and, unlike previous writing classes she had taken, she had "no fear of being graded, because I knew if I was doing it, at the end I was going to get the points because I tried," further stating it was the not as stressful of an experience for her because "it was progressive and consistent." These students' interview responses indicated that communities were formed within their workshop practice, peers helping solve concerns about ideas and writing worked to "[validate]" Student C's ideas. Positive terms and phrases such as "it's okay," "progressive," "consistent," "not perfect," etc. indicate an awareness of the paced design as specifically beneficial to aspects of confidence, writing, and comfort. Additionally, many students — such as Student C — compared previous experiences of writing to her experiences in my course without my inquiry, indicating that she is able to articulate this practice rooting this in prior knowledge to showcase the benefits of the paced design to her other experiences.

Likewise, students self-reported growth and confidence in themselves and their writing skills in the self-reported reflections and my observation notes. Student E stated: "[M]y writing definitely improved since the start of the semester. Going back to high school, my teacher didn't really motivate me, in fact he mostly just brought me down. I was able to pick myself back up, start fresh.... [Workshop] helped further my knowledge of rhetoric and how to apply it in different ways to convey different meanings. It taught me that changing one little thing can change the whole overall meaning completely." Student E's reflection response exemplifies the recognition of her abilities before and after workshop: noting that in high school she felt discouraged, yet her involvement in writing shifted her perspective of writing and her confidence in her writing. She articulates this confidence well, using the declarative modifier "definitely," using positive phrases such as being able to "pick 
[herself] back up, start fresh" and terms like "helped" and "improved." Student E's ability to articulate this practice of writing with her past and current writing experiences elicits connections to Bartholomae and Bruffee's articulations of practice and discourse as well as Shaffer's community of practice. Self-reported confidence and growth was consistent across all seven participants, as was observed in their workshop sessions through their ability to discuss their work more openly and comfortably with others, prompting fluid discussion with their peers, and indicating a relaxed body language and tone. The students were able to not only grow confident in their own rhetorical skills and knowledge but also comfortably learn from their peers in the process; students were able to learn from their peers' work, and rather than view it as a competition between each other, they were actively and eagerly learning as a part of a community within their workshop groups, not working alone as a "solitary author."

\subsubsection{Fall Case Study: Student G}

This case study focuses on an interview with Student $G$ who was in her first semester of her fourth year at Chapman University in Fall 2020. In her collective workshop reflection, she initially expressed that her original perception of the workshop design was negative, yet that changed by the end of the semester: "I think the idea document sounded pretty dumb to me at first but it helps so much to really consider what you TRULY felt passionate writing about and were able to consider if it would be doable....I really think the workshops worked well with this class and the structure was great." In our interview, I dug deeper into the concepts of community of practice and the paced design that she invoked within her reflection.

To first understand how Student G's initial perceptions of the workshop design began, I asked about her prior experiences with workshop and feelings toward writing prior to my class. She explained that she took Honors and Advanced Placement classes in high school, to which 
she described the writing that took place within those classes as "a waste of time." She stated when she first saw my syllabus with workshop on it, she was reminded of those classes, and instantly tacked a negative perception of writing onto the workshop within my course, referring to the workshop as "dumb."

She also discussed her previous experiences with workshop in a creative writing class in college, where she referred to it as "nerve-racking" since the workshop was a whole-class workshop. She expressed concern when it was time for her work to be reviewed, since the class “would basically talk like [she] wasn't even there." These perceptions of whole-class workshop harken back to Oleksiak's slow peer review approach, wherein emphasis on the "improvement imperative" is present while resisting opportunities for queer rhetorical listening; instead, Student $\mathrm{G}$ felt isolated and judged rather than her work being meaningfully and constructively read. Likewise, she noted her anxieties toward the workshop were also attributed to the fact that she is not an English major, so she felt she "did not have the experience" that everyone else in the class had with writing. Also, within this creative writing workshop her work was graded by the professor as it was read aloud to the class, which made her worried about producing a strong final draft to show to the class. Student G's experience with workshop evoked notions of Cooper's "solitary author" trope, wherein the writer "[makes] the final revisions necessary to assure its success when he abandons it to the world of which he is not a part... [directing it] at an unknown and largely hostile other" (Cooper 366). Student G's recognition of her place in an English class not as an English major made her feel outcast and less confident in her abilities, while making the peer review process anxiety producing. Harkening back to Bartholomae's notion of discourse, Student G had to re-invent the university by mimicking creative writing terms to both feel comfortable within this environment as well as simply pass the class. 
When I asked Student G how and when her perceptions about workshop in my class changed, she stated about halfway through the course she had a "realization" that the workshop was "actually helpful since it cleared up a lot of things" that she could ask her peers and "work together to clear up concerns about the prompt" and her writing. She stated working with her peers helped her "understand how the paced design truly was effective for [her]" in that she could use her voice to explain her writing within my class rather than sit silently and be "embarrassed." Also, she stated she feels more confident in writing "than ever before" because working with her peers helped her realize that she "actually gives good advice" to others, claiming that the workshop experience helped "build [her] confidence and trust [her] ideas." Now, she states the paced workshop made it "easier for [her] to ask for help" in her other classes and does not "wait until the last minute" to start a writing assignment. She cited one of her current courses where she has planned the major writing assignment in advance, feeling comfortable to re-read her writing and "take the time" to write, something she had "never done before" since she was "embarrassed" to read her own writing even to herself. She also stated she is now more willing to "help others and know[s] how to give feedback." She ended the interview by saying she has "definitely seen an improvement" in her writing and planning and she "attributes it to [my] class."

Student G's ability to articulate how the paced workshop has helped her now in other writing situations, including in situations that do not require peer review, indicates that her confidence and comfortability with writing had changed since her time in the creative writing workshops. With Student G using declarative terms and phrases throughout such as "than ever before," "definitely," and "never" help provide the stark contrast of writing from before and after her experience with the paced design. An aspect of the interview that struck me the most was that 
she was able to "trust [her] ideas" both in terms of her own writing as well as the advice she gives to others. As a whole, this interview evoked Shaffer's community of practice in that an epistemic rhetoric was produced wherein the values, knowledge, skills, and identity were reinvented in the paced design. Student G was able to find comfort and confidence in an English class, learning new skills and "mobilize the practices from that community in new situations" (Shaffer 411). While I did not aim to discover whether specific skills had "transferred" as part of this study, I was happy to hear that Student G's values and identity as a writer were positively affected after the conclusion of this course.

\subsection{Fall Conclusions}

Upon completing the first phase of my study, I was pleased with the variety and consistency that confidence and growth were applicable across the seven participants. While, admittedly, I was unaware of how deep I was going into this study in terms of content to sift through, I found the results to be uplifting in my perceptions of workshop: most notably, I was surprised at how strongly my students bonded during the workshop, establishing friendships that were meaningful not only to their work but also to themselves as students who were forced to learn online due to COVID-19. This observation invoked Shaffer's communities of practice, with students not only discussing the project within their own discourse but also establishing a connection of values, bonding over anxieties surrounding online learning and life as a first-year student. Yet, I acknowledge that online learning may have bolstered this ability to establish communal identities and bonds among the students given how distancing the platform is; however, this only reiterates the importance of allowing for a space for communal identities and bonding to flourish through collaboration regardless of online or in-person instruction. As a whole, this first phase of the study had proven that allowing for opportunities for students to 
explore their writing process both individually in completing the workshop material and collaboratively when discussing with their peers increases their confidence in themselves, their writing, and their student identities. Although I was not convinced that this workshop setup was attributing to this confidence and growth, I aimed to further explore the efficacy of workshop in the Spring phase.

\subsection{Spring Results}

In the Spring 2021 semester, I replicated this study with eight participants from my English 103 Rhetoric of Environmentalism course. For this second phase of the study, I decided to organize the results by project, outlining and analyzing the students' reflections and my observations, with case studies and analysis at the end of this section.

\subsubsection{Project 1 Workshop}

Project 1 was a multimodal project where students created a piece of environmental activism out of their own interests and designs.

Having completed the first phase of this study, I entered the new phase curious to see if confidence and growth would be self-reported by the students in their reflections as well as my observations in their workshop sessions. Likewise, given this was the first workshop process of the semester in the midst of online learning, I similarly questioned the confidence that these students would exude. Yet, the eight participants showcased there was an exceptional amount of confidence, comfort, and ease of anxieties. As Student K stated, "It is not often in-person or on Zoom that you get the luxury of receiving feedback from your peers in a really comfortable and controlled environment. The use of the discourse generators was extremely helpful for me as I was easily able to control the conversation and things never felt awkward." Student K's diction 
of "luxury" and the phrase "really comfortable and controlled environment" highlight the paced design as simultaneously helpful and comfortable for her, harkening back to Bruffee and Bartholomae's notions of discourse and articulation due to her ability to articulate the discourse of this practice in her own terms. Here, Student $\mathrm{K}$ is metacognitively reflecting on exactly how her experience in workshop affected her, using declarative terms such as "extremely helpful," "really comfortable," and "I was easily able to," "things never felt awkward." Student L similarly felt comfortable, stating: "I loved this workshop, not only cause of how helpful it was but it also was a nice way to get to know my classmates better and being online I really enjoyed that." While several participants were self-reporting the increased confidence and comfortability in working with peers and discussing their work, I noticed similar means of comfort in my observations: Student $\mathrm{H}$ had their camera on in each observation and was nodding, taking notes, and being visually receptive. Likewise, commonly heard phrases throughout my observations were "I really liked your idea," "You did a great job," and "I'm really excited to see your project." Positive reinforcement was consistent across all observed participants; these phrases were stated by the participants to their group members. These open and frequent exchanges of these words of encouragement further implicated that the students felt comfortable within their group dynamic while the positive reinforcement through the praise can encourage the students' confidence and, by proxy, their comfortability with their ideas and writing.

To further understand growth and reflect on Howard's deconstruction of the authoritative teacher/student hierarchies, what role did this workshop help empower students while also offering an opportunity for them to bond? In her reflection, Student I stated: "I loved the way this workshop went, and I'm glad I reached all these personal discoveries. I also really want to thank [partner] for guiding me through my decisions and creating new perspectives." Student I's 
reflection response suggests an articulation of practice, indicating that her peers helped her articulate her ideas, offering "new perspectives" and guidance for her; her reflection also indicates that the practice itself allowed the students to build both personal and academic relationships, with her partner helping her academically while creating bonds of friendship through this practice. Student I's use of "love" indicates the workshop had significant positive impacts on her, while the phrase "I also really want to thank [her partner]" showcasing the extent to which her time spent in workshop was beneficial to both her "personal discoveries" and the bonds they created. Similarly, Student O wrote: "How all of the workshop was set up made me feel super comfortable and not overwhelmed in the slightest. I loved my peer reviewer as well because she did a great job of not being judgmental yet would openly give feedback so I am glad that the peer review aspect was part of all of this." Again, Student O stated she "loved [her] peer reviewer," and phrases such as "she did a great job of not being judgmental" and "I am so glad that the peer review aspect was part of" workshop demonstrates an articulation of community of practice and its benefits. The language both Student I and Student O used were indicative of workshop being beneficial because of the collaborative aspect, indicating through words such as "loved," "openly," "glad," etc. that this was effective for them. Students I observed in workshop were able to give constructive criticism while being respectful, uplifting and maintaining a casual tone. Yet, the students were not afraid to get to know one another: students discussed their majors, upcoming workshop assignments, other classes, and COVID-19. It seemed as though each group had a conversational "leader"; namely, Students J, K, L, and O would instigate conversation among their peers after a few seconds of silence once everyone shared their feedback. This would usually occur approximately fifteen minutes into the tweny-minute workshop session. While natural leaders produced as a result of this workshop was not initially 
anticipated nor expected, it is interesting to consider the aspects of collaboration in this regardwere these natural leaders produced as a result of the online format, or would this have occurred in-person as well? Regardless, it was an interesting result of this first round of workshops.

In their reflections, the eight students indicated their preferences for workshop materials by answering the following two questions:

1. What day of the workshop was most helpful to you in terms of receiving peer feedback?

Table 1. Project 1 Most Helpful Workshop Day for Feedback

\begin{tabular}{|c|c|c|c|}
\hline Idea Document & Detailed Outline & Rough Draft 1 & All 3 Documents \\
\hline 2 & 2 & 2 & 2 \\
\hline
\end{tabular}

Interestingly, students indicated that receiving peer feedback for workshop varied; two of the eight participants stated all three days were helpful for them, not choosing a specific day like the other six. In terms of their answers, students stated the Idea Document was helpful for "[setting] the tone of my future project. I am very indecisive, so hearing advice was very helpful," as Student I stated, and Student N wrote, it was helpful "because my peers told me what project idea they thought would be best. I am really glad that I stuck with the idea of photography." Students who indicated the Detailed Outline was most helpful stated "I got to ask the more technical questions to see if the video was going in the right direction" and "because at this point in the project it I had a clear idea of what I wanted to do and knew better what to ask," as Students J and L reported. The Rough Draft 1 was valuable for Students H and K because "This was where they could actually see what might need tweaking or editing with the actual product instead of talking about the ideas that went into making the product (which is also extremely 
important)" and that it allowed "my peers to finally be able to envision my vision through my work was incredibly exciting and helpful as I went into crafting my second rough draft.”

2. What day of workshop was most helpful to you in terms of the workshop material ("Idea Document," "Detailed Outline," "Rough Draft 1")? What material helped you think the most thoroughly about your ideas, plans, and writing? Why?

Table 2. Project 1 Most Helpful Workshop Day Material

\begin{tabular}{|c|c|c|}
\hline Idea Document & Detailed Outline & Rough Draft 1 \\
\hline 1 & 4 & 3 \\
\hline
\end{tabular}

While the Detailed Outline seemed to earn the most votes in this reflection, Student K stated the Idea Document "was very nice because it felt like a very casual way to just get all of my thoughts out in an organized manner." Students who stated the Detailed Outline wrote "I was able to go into detail as to how exactly I wanted it all to look, without any stress of actually having to recreate it quite yet. I was able to get feedback and change stuff around before I even set off to take the picture that I had planned for" and how "working on [the project] with my partners helped me to see the flaws in my plan to execute the project. It also helped me find the gaps in what was required of me and what I was not meeting." For the Rough Draft 1, students explained: it "allowed me to get a based idea of what I wanted rough draft \#2 to look like. After doing rough draft \#1 it was easier to complete rough draft \#2 because I had a set idea in mind" and how it "was almost like the real deal so I put more effort into it and seeing my partners feedback really helped because there were some minor adjustments in some places and major in the others, so i got those out of the way and a lot of questions I had were answered." 
Although I was anxious to see how students would respond to this workshop so soon in the semester, the participants seemed very receptive and appreciative of workshop in their reflections. Based on these reflections, all participants indicated a mastery level of workshop, indicating to some degree that workshop helped in their planning, personal confidence in writing,

enjoyed working with others, and achieving the ultimate execution of the project. Reminiscent of Elbow's “teacherless classroom” and power dynamics of Martorana's "figured worlds" of collaboration, students found an experience that was driven by their own voices and decisions to be comforting and helpful without reporting that workshop created issues of debate or struggle. As Student I claimed, she "thought it was beneficial to learn how to communicate with a partner and receive advice." Thus, even within the first workshop process, students began to become a part of a community of practice with their peers.

\subsubsection{Project 2 Workshop}

Project 2 was an interview with a person of the students' choice to understand and analyze their subject's and their own varying identities related to environmentalism.

In the Fall phase of my study, I did not get as strong of reflections on identity as I had initially hoped. Yet the Spring phase seemed more promising in offering depth to identity, with Student K stating:

"The workshop for this class allowed me to really dive into the purpose of this project not only for this class but for myself as well. This interview holds a near and dear place in my heart and was truly transformational for my understanding of what intersectional environmentalism is through an Indigenous woman's lens. This project has really empowered me in the way in which I can relay information from others in an impactful and respectable manner." 
Student K used purposeful and positive terms, emphasizing how the project "empowered" her both personally and academically. Likewise, Student K metacognitively reflects on the rhetorical significance of the project that our workshop helped to illuminate and encourage deeper thinking of aspects of audience and purpose. Similarly, Student J mentioned that they are "still having a hard time feeling OK using my voice when talking about environmentalism and using more personal language to describe the situation since it is so close to my heart... [but the workshop] made me think about my choices regarding how to convey the message I was trying to get across." Both students indicated some aspect of personal identity surrounding intersectional environmentalism — or "eco-racism" - in relation to their family and friends. Likewise, both accredited the workshop process for making talking about such a difficult topic more digestible. Student $\mathrm{J}$ is self-reportedly from a mixed race background, so this project offered an opportunity to explore this more deeply while allowing for space in workshop to collaboratively discuss these facets of their identity within the project, opening up abilities to, as Bruffee explains, uplift the "emotional aspect of learning, tapped through the relationship, the emotive tie, developed among several students organized to work collaboratively," ultimately breaking the teacher/student hierarchies and simultaneously supporting reflection and discussion of the self and one's feelings (746). As Student J wrote, they initially felt uncomfortable writing about this topic, yet they eventually realized they were "able to explore this more and practice it since it is something that we have been told we are allowed to do and are encouraged to do so."

In my observations, I noted that all participants observed were relaxed and casual in their mannerisms yet thorough in their descriptions. As observed in the Project 1 workshops, Students $\mathrm{J}$ and $\mathrm{L}$ actively maintained this casual and friendly tone. Toward the end of their session with about three minutes left, Student J commented on another student's pet dog wandering in the 
frame, sparking laughter and smiles, as Student J swiftly segued into asking about any other questions from the group, to which the group responded they felt comfortable with their work. Likewise, Student L, with approximately seven minutes remaining after completing their workshop duties, there was roughly one minute of silence when she asked about the COVID-19 vaccines, to which her group openly discussed their anxieties about COVID-19 and their preferences on vaccinations. Like Student J, Student L swiftly asked about the other members' interview processes and answered a question from her peer about her interview. In both breakout rooms, all individuals had their cameras on. Contrastingly, when observing Student I and K, their group all had their cameras off. However, this notion of online presentability becomes moot when, during my observations, these students were exceptionally receptive and displaying prospects of growth and confidence, stating phrases such as "That is going to be very helpful, it makes a lot of sense when you put it that way" and "Thank you, that helps me a lot" while still offering positive reinforcement such as "Everyone did a really good job" and "You could see your passion for [this topic] in your project." Arguably, the students with their cameras off were more verbal in their appreciation and display of understanding their peer's feedback than those with their camera on. While this could be chalked up to personality type, perhaps this virtual conversation in workshop was indicative of the need to present-and perhaps overexaggerate this presentation—verbally to instill a similar sense of community. When talking about the audio recording of her interview, Student I ironically mentioned how difficult it is to have conversations over Zoom, that they feel distanced and "not authentic." While this inauthenticity was not evident in their workshops, I grew curious as to the effects that one year of online learning was beginning to have on my students in our workshops. 
As they had in Project 1, seven of the eight participants indicated their preferences for workshop:

1. What day of the workshop was most helpful to you in terms of receiving peer feedback?

Table 3. Project 2 Most Helpful Workshop Day for Feedback

\begin{tabular}{|c|c|c|}
\hline Idea Document & Detailed Outline & Rough Draft 1 \\
\hline 2 & 3 & 2 \\
\hline
\end{tabular}

Consistent with the first round of workshops, students were evenly split in what day of workshop offered the best feedback while this round earned one more vote for the Detailed Outline. Although one student did not complete the reflection for this round of workshops, the seven participants' feedback offered more context to the why the Detailed Outline was beneficial to them. As Student H stated, "I always feel like the detailed outline is the most helpful when it comes to receiving feedback, as my peers will help me make sure that all my ideas are clear, concise, and effective for what I am trying to convey before I spend time writing my rough draft." Likewise, Student I stated the Detailed Outline stage of writing was when she "[believes] this is when I always need guidance, making a clear focus for exactly how I want my project to turn out. I usually have many paths I want to take, and I like hearing how another perspective would perceive it." Student L said the Detailed Outline was when she "[thinks she] needed the most guidance and had the most questions for my peers." While the Detailed Outline was favored in this round, the Idea Document still earned positive feedback for "[helping] help me sort through the things that I needed to fix in my interview and what things to head for to get to a better quality" and how "my group helped me narrow down my ideas and make up my mind as 
to which direction to go." Similarly, the Rough Draft 1 reportedly helped students "hone in on everything I wanted my project to include and the most effective way to go about it."

2. What day of workshop was most helpful to you in terms of the workshop material ("Idea Document," "Detailed Outline," "Rough Draft 1")? What material helped you think the most thoroughly about your ideas, plans, and writing? Why?

Table 4. Project 2 Most Helpful Workshop Day Material

\begin{tabular}{|c|c|c|}
\hline Idea Document & Detailed Outline & Rough Draft 1 \\
\hline 2 & 1 & 4 \\
\hline
\end{tabular}

While the Rough Draft 1 earned high votes in the first round, the Detailed Outline was clearly beat this round. Students reported that the Rough Draft 1 was helpful in regards to how it offered "a clear write-up of how I want to conduct my project, my overall intention, and its importance" and allowed students to "see the flaws in my work more than I did in the idea document and the detailed outline." Student H also stated it was helpful: "to show my group the early stages of my draft of my project, and to make sure that I am on the right track when it comes to following guidelines and the structure for the project. They can also critique my writing and ideas which is also helpful." Yet, the Idea Document still earned equal votes for both questions in both rounds, Student K claiming "it allowed me to essentially word vomit all of my ideas in an organized manner rather than just a bunch of scramble in my head which is not very productive or helpful. It is a very low stakes way for me to materialize all of my thoughts." These responses rekindled aspects of Anne Lamott's "Shitty First Drafts," wherein the concept of "almost all good writing begins with terrible first efforts. You need to start somewhere. Start by getting something anything - down on paper" (Lamott 2). For both rounds, it seems this "first draft" of an Idea 
Document is effective both for student writing processes as well as student learning. Interestingly, the Detailed Outline earned one vote, the lowest score so far in this phase.

As this workshop round completed, students seemed more at ease and comfortable with their peers and their writing, stating they feel "super confident!" and that "this workshop as a whole benefited me because I was also able to learn more about certain topics that I have not thought about before. The workshop also helped since I had to think about what audience to direct it at." Many of the participants echoed similar benefits of workshop, again indicating a mastery level of workshop as their responses aligning with Student H's statement that he "enjoyed working with my partners who were able to provide feedback on my idea documents and anything I had to say to them in the zoom breakout rooms related to my project. Getting other points of view and opinions from my peers offers insight from angles that I haven't looked at before."

\subsubsection{Project 3 Workshop}

Project 3 was a research proposal, where students choose an environmental issue and propose a solution for a community, group, or organization of their choice.

Having completed all three workshops, students' reflection responses showcased a deeper articulation of the role workshop has played in both their personal and academic lives. For example, Student K writes that "The workshop as a whole was incredibly beneficial for me as we all got to bounce ideas off of one another and make suggestions that could even be applicable to our own writing which allowed me to be self-critical as a student." Student K evokes these concepts of collaboration and community further in her collective workshop reflection, stating "Before this course, I struggled to keep up with all of the writing assignments in my classes and had difficulty finding the motivation and incentive to keep going but in this course the incentive 
of peer feedback was incredibly helpful for me. Additionally, positive feedback from my peers increased my confidence in my own academic writing which was also incredibly empowering." Student K's articulation of the practice becomes clear within her largely positive terms and phrases, such as "incentive," "motivation," "increased my confidence," "incredibly empowering," and "incredibly beneficial." Her ability to contrast her approaches toward and confidence with writing prior to this class to after the workshops occurred showcase that Student $\mathrm{K}$ has become a part of a community of practice, wherein her reflections highlight the articulation of her role within that community. Likewise, Student M makes similar articulations of practice, noting:

“Honestly, I don't know if it's just this project specifically but I feel the breakout rooms for this project have been very productive for me and there hasn't been one where I [haven't] got a ton of great opinions and was able to make easy but needed changes... [my confidence is] only gonna continue to improve if I keep my mind to it, because once you get through the beginning phases it just gets simpler and you can continue to expand... I think the most important thing about workshop that I've realized is you can never be perfect. Your writing styles improve because if you remember what you needed to change before, you won't make that same mistake again."

Student M similarly articulates the benefits of this practice, reflecting on the peer collaboration, his confidence, the paced design, and perceptions on writing. When observing Student M, he would consistently offer positive reinforcement for his peers, offering constructive feedback in terms of audience and organization while uplifting his peers' ideas, noting both of his partners' ideas "are really cool topics." Yet, when it came time to discuss his own ideas, he prefaced the conversation with saying "I feel like this is a dumb topic to do" while laughing. His peers 
immediately offered positive reinforcement, such as "No! I actually love that topic. You should do it," and constructive feedback, like "It helps to focus on issues of supply and demand since it seems like there aren't any immediate consequences right now." After talking about his ideas for a few minutes with his peers, Student $M$ thanked his peers, stating that it made him feel better about choosing his idea. This observation harkens back to his reflection, wherein he no longer feels the pressure to be "perfect" and openly admits his struggles and lack of confidence. Like other students have mentioned, Student M seems to find value in the collaborative aspect of workshop, gaining confidence in talking through his ideas within the community he is part of.

In a similar respect to Students $\mathrm{K}$ and $\mathrm{M}$, Student $\mathrm{O}$ voiced appreciation for the peer collaboration in workshop: "The peer review groups were also super helpful because I was able to get other viewpoints on my ideas and they really helped me to explore different routes." Likewise, Student O credits the paced workshop for helping her "get all my thoughts out, not get overwhelmed, and makes sure I am on the right track before I even start writing." Student O's response invokes an articulation of the paced design while expressing gratitude for the community she was a part of during workshop, harkening back to Lamott, Bruffee, and Shaffer.

In their reflections, the eight students indicated their preferences for workshop materials for Project 3:

1. What day of the workshop was most helpful to you in terms of receiving peer feedback?

Table 5. Project 3 Most Helpful Workshop Day for Feedback

\begin{tabular}{|c|c|c|c|}
\hline Idea Document & Detailed Outline & Rough Draft 1 & All 3 Documents \\
\hline 3 & 1 & 3 & 1 \\
\hline
\end{tabular}


In this last phase of workshop, the Idea Document and Rough Draft 1 earned equal votes. Students wrote about how the Idea Document worked to solve confusion about topics and approaches to the project, where Student L wrote "I wasn't sure which of my ideas I wanted to work with and so getting insight from my group helped me to choose the topic I went with" while Student M noted "I was kind of lost towards the beginning and my partners did a great job helping me make a decision on what I wanted to do.” Both Student L and Student M suggest that their confusion prior to the first day of workshop was resolved, as their peers largely contributed to helping ease the anxieties and concerns surrounding their ideas, further suggesting that they trust the community they were a part of for guidance and assistance. In terms of Rough Draft 1, Student $\mathbf{J}$ writes "I got the most information from my partners about how to really focus my structure on both students and faculty and also be able to speak out loud some of the ideas that I had and have them give me direct feedback on them." Student N similarly suggested the Rough Draft 1 "helped me because I realized what I need to add and how I should structure the information that I already provided." Students who voted for the Idea Document and Rough Draft 1 strongly emphasized the ways in which their peer collaboration affected the progression of their writing and ideas.

2. What day of workshop was most helpful to you in terms of the workshop material (“Idea Document," "Detailed Outline," "Rough Draft 1")? What material helped you think the most thoroughly about your ideas, plans, and writing? Why?

Table 6. Project 3 Most Helpful Workshop Day Material

\begin{tabular}{|c|c|c|}
\hline Idea Document & Detailed Outline & Rough Draft 1 \\
\hline 1 & 6 & 1 \\
\hline
\end{tabular}


Regarding the most helpful material for Project 3, Detailed Outline earned the highest score yet throughout this phase. Student K wrote that the Detailed Outline "allowed me to figure out [generally] how I wanted to structure the piece without having the obligation to write down every component needed but rather just mapping out a plan that will make the writing for myself easier later on in the process." Student K's acknowledgement of the paced design in respect to her writing process suggests that this paced design is effective for and her writing approaches. Student O similarly wrote that "it is the best way for me to get all my ideas out and clean it up before I even start working on the project. This makes sure I stay on track and don't lose sight of the prompt." Both Student K and Student O's articulation of the paced design in conjunction with their individual writing styles work to showcase how the paced design can eliminate anxieties of producing a "perfect" product and, instead, indicate that "mapping out a plan" can help students "stay on track." Student J expressed similar feelings toward the material, writing "It gave me more direction about which idea I wanted to do more and helped me decide what rhetoric to use within the project," while Student M noted "I made a huge jump from the idea document to the detailed outline. My paragraphs got longer and more specific, my solutions were a lot better. I added a lot of sources and even my partners agreed in workshop." The transition from Idea Document to Detailed Outline can be overwhelming, yet it was met with praise and positivity by Students $\mathrm{M}$ and $\mathrm{J}$ in that it offered "more direction" and specificity as they inch toward the rough drafts.

While the results of the study indicate that implementing a workshop in a college classroom is beneficial for students, where does this leave the paced design? Students began to reflect on the paced design more specifically in their collective workshop reflections, with Student K noting her initial perceptions of the paced design as overwhelming: 
"The pace was a bit intimidating at first as I had a lot of fear that I would experience some form of writer block, but the openness of the prompts for all of the projects allow me to explore topics I was passionate about rather than those being imposed on me and therefore I would get excited the next time a workshop material was due because it was just another opportunity to articulate feelings I had about subjects I was and am passionate about."

Student K openly acknowledges that the pace was "intimidating at first" given the number of assignments, yet she ultimately would be "excited" to complete these projects in a paced approach as they offered more opportunities to "articulate [her] feelings" and passions. Likewise, Student I wrote in her collective workshop reflection that "the pace gave me clarity and assurance in my writing" and "helped me feel secure by the time of Rough Draft 2. I understood my audience, my purpose, what I wanted to learn out of it, and what I wanted my audience to feel. I definitely feel like my writing has improved. I have better intentions when writing and can finish without feeling rushed or lost." Student I's ability to connect her rhetorical knowledge to the paced design showcase an articulation of discourse as a result of this practice, wherein Student I declares she "definitely" has seen improvement in writing and her "intentions" with writing. Similarly to Student M, feelings of being "lost" in the writing process dwindle because of the paced design and collaborative aspects of workshop, suggesting a slower approach to writing and collaboration are effective in easing common anxieties and concerns of students.

Therefore, to explore the effectiveness of the paced design further, the case studies below aim to understand the role the paced design had for the students in more depth than the reflections could offer. The information in the case studies stem from the interviews conducted with willing participants from the Spring phase. 


\subsubsection{Spring Case Study 1: Student K and Student O}

This case study follows Student K and Student O's opinion on the paced design of the workshop and how it affects their confidence and writing, especially when rooted in their similar previous experiences of peer review. Student $\mathrm{K}$ is a first-year student in Health Sciences whose prior experience with workshop in high school was "frustrating," yet she feels "empowered" by the paced design of this workshop and she "realizes [she doesn't] need someone holding [her] hand" throughout the process. Student O is a first-year Religious Studies major, who described her previous peer review experiences as "pointless," but the paced design helped her perceptions of writing "do a complete 180 " where she is able to take writing "step by step" and "push the boundaries of writing."

She referred to her previous peer review experience in high school as "elementary... [it] did not give us full autonomy" since the teacher would "stand over us" as they completed the questionnaire and she had "no opportunity to say what I need or to ask for help." As a result, she would "just ignore and delete the comments." Instead, Student K would ask her father to peer review all of her writing. Student K's word choice of "elementary" and "autonomy" showcase that Student K understood what exactly she wanted from a peer review experience: she wanted maturity and autonomy; she wanted to feel comfortable in the experience rather than feel "watched" by her teacher and pressured to write comments the teacher would approve of; she wanted to use her voice to ask for help and explain herself in the classroom rather than feel helpless. Likewise, Student K's word choices of "autonomy" and "elementary" are reminiscent of writing studies discourse, showcasing she can not only articulate the benefits of this practice but also showcase she is part of this community of practice referencing the discourse of these communities. Her recognition of what she wants is furthered by her admittance to asking her 
father to look over her work, someone she trusted would actually read it. Student K's ability to root her experience with the paced design in conjunction with this experience indicates a strong articulation of the practice as helpful and meaningful to her, especially with the collaborative aspects she was deprived of earlier in her academic experiences.

In our interview, Student K cited the Idea Document as most helpful to her, since it "gave [her] opportunities to word vomit onto the page, go in a multitude of directions, and not be stuck to one way of doing something." This harkens back to Lamott's "down draft," wherein freewriting, or word vomiting, takes place to simply get all of one's ideas out on paper. Similarly to Student $\mathrm{G}$ in the Fall phase, Student $\mathrm{K}$ also found the paced design helpful for resolving procrastination in that "so many assignments are a motivating factor, the project is growing and developing... the structure is helpful to avoid procrastination from happening." She mentions the paced design has helped with her "internal motivation," offering an "incentive to turn in something" and to "not fall behind." She referenced her experience with high school English classes, where she learned "to be a fast writer" with timed essays but they "[did not] include a vantage point where we see where we can go," stating "it's more gratifying" using the paced design.

Student $\mathrm{K}$ also cites the collaborative aspect of this paced design as offering her "more autonomy and you can have an opportunity to trust we can have a productive conversation." She recalled a workshop session for Project 2, where her group had an extended conversation about one of the peers' topics not solely in the context of the prompt, but because they were interested in the topic and wanted to talk about it casually. She stated that talking about the workshop material encouraged this opportunity for discussion, which was something she valued heavily from this experience. This recalls notions of community of practice, wherein the students create 
relationships with one other that stem from this academic discourse, bonding over a peer's project topic for Project 2. For Student K, it seems the two most beneficial aspects of the paced design was consistency in terms of both collaboration and writing. Student K's articulation of the paced design offering an opportunity to have "a productive conversation" and a "gratifying" experience highlight her ability to articulate that this workshop was beneficial both in terms of her personal expectations of the workshop as well as her academic goals. She ends the interview by expressing that the paced design helped "build her independence and confidence in [her] own abilities," noting that she has not asked her father to peer review any of her writing this semester.

Similarly to Student K, Student O cited the Idea Document as most helpful because you "sometimes you get an assignment and start freaking out," stating that she would often write in states of panic and it would "turn out bad." Yet, she noted that the Idea Document helped to "word vomit" her ideas and "break [the project] down" to be "more achievable and less stressful." Again, this evokes Lamott's "down draft," wherein "you need to start somewhere. Start by getting something — anything — down on paper" (Lamott 2). For Student O, her first exposure to peer review was in an Introduction to Religion course, which prioritized strictly online feedback as they leave three comments in the comments tool on Canvas. She noted that the feedback was always anonymous since the professor wanted them to be honest, but the feedback she received would end up being "super harsh since they could hide behind a screen," and she found it difficult to never have an opportunity to explain her ideas or opinions. Student O similarly seemed to value the collaborative aspects of writing, striving for a sense of "autonomy" and belonging within the peer review process. Similarly to Student K, Student O would have her mother and sister peer review her work for her classes, yet the paced design offering frequent meetings with peers helped her feel "more comfortable and more personal" within the 
experience, noting that the peers in this paced design offered "constructive criticism" in a respectful manner, which helped her to feel more relaxed.

Student O directly stated in the interview that the paced design "upped [her confidence]," confiding in me that "[she] was dreading this class and [she hated] writing" initially. Yet, she further explained that this paced design "changed how [she plans] everything, that it doesn't have to be all at once and [she] can stay on track." She gave an example of how she implements this confidence in other writing situations, sharing an experience about a paper she wrote for an Introduction to Islam course this semester. She noted that she followed the project prompt for the class yet made some personal connections and used rhetorical strategies learned in our course while connecting it to her research throughout the paper. She explained that she got an A on the paper, and the professor "loved it" stating that "it was so different than anything he's seen before." She stated that she "gained so much confidence in writing" and that she can be "open to writing not just what the professor will like but if I like it too." She explained she recognized that her voice and opinions matter, and that she can be "risk-taking" with her writing. Student O, similarly to Student K, seemed to value the opportunities to explore their own opinions and interests throughout the workshop process, something they both lacked in their previous experiences. For Student O specifically, she transferred these feelings of confidence and comfort gained from the paced design with writing into her other courses, something she initially "hated" and "dreaded."

Likewise, both students mentioned that pacing the writing throughout the semester helps ease anxieties, whereas other courses "just throw the project at you," according to Student K, and if I had assigned the project prompt without a structure "there would be no spark to start writing... the phasing of the workshop helps set us up for success," according to Student O. For 
both Students K and O, they had similar prior experiences with peer review, wherein the paced design altered their perceptions of writing and peer review and allowed them to recognize their abilities, confidence, and the role that collaboration plays in the process.

\subsubsection{Spring Case Study 2: Student N}

Student $\mathrm{N}$ had the most explicit articulations of the paced design in all interviews I conducted, noting directly that the paced design has helped change her perceptions of writing and "build [her] confidence in expressing [her] own ideas and speaking about [her writing]." However, unlike Students G, K, and O, Student N had no prior experience with peer review or workshop. Student N is a first-year student majoring in Business Administration.

Student N stated that in the beginning of the course she was "scared to talk about [her] opinions" and reflected back to when she was in high school where "[she] didn't talk in class because [she] didn't want to be wrong." She connected this back to the Idea Document, stating that this day of workshop helped her realize "you can have these ideas" even if they are not "perfect," mentioning that the paced design helped her "feel more comfortable talking about topics and that it's not actually that bad." She reflects on this feeling of anxieties surrounding discourse later in the interview, stating that she "hated talking and didn't want to share or be judged" by her peers. She stated that because of the paced design, she is comfortable sharing what she thinks with her peers and now she "loves to participate in class because [she] learned in workshop that not everyone thinks the same way, but it's fine to think differently. It opens up opportunities to learn that this is okay." These notions of anxieties and discourse harken back to Bartholomae and Bruffee's discourse approaches in that Student N was fearful to insert herself into the discourse communities of academia, wherein "it is very hard for [students] to take on the role - the voice, the persona — of an authority" figure or discourse (Bartholomae 591). Rooting 
the academic discourse in more digestible terms through the process of the paced workshop allowed Student $\mathrm{N}$ to grapple with this notion of "imposter syndrome" in the discourse community more easily, being able to confidently share her ideas in a small group setting before translating that to the whole-class setting.

Additionally, she noted that the Idea Document causes her to consider her ideas more critically, and that the paced design encourages her "to think of something and trust [herself]." Likewise, she mentioned she "used to tackle papers head on," which caused her to become overwhelmed and procrastinate. She discussed her time in AP English classes, where she would "write as fast as possible" and "only cared about passing the test." She connected this back to the paced design, using her experience in AP English to establish the contrast between the two experiences; she stated that the "paced design is more of a learning process, there is no pressure... I don't have to perform for anyone, I do what I truly want to do." Terms such as "learning process," "perform," and "no pressure," highlight Student N's articulation of the paced design in contrast to the experiences in AP English, almost subconsciously offering recognition of her growth and confidence in herself beyond her direct statements of growth and confidence. Most notably, Student N uses the word "truly," which Student G used repeatedly as well; the use of this word implies that there was authenticity or genuine action occurring in this paced process, and that they did not have to feign interest or skill in order to complete the assignment.

She also credits the collaborative aspect of the workshop with "boosting [her] confidence" due to being in "a super supportive environment helps build [her confidence]" in her ideas and what she brought to class. Like Students K and O, the collaborative aspects in regard to positive reinforcement and praise interconnect with notions of confidence and comfortability.

Toward the end of the interview, Student N stated that if she had not had so much exposure in 
talking with her peers about her ideas and writing, she likely would not have been as confident in her ideas and participating in the larger class. She credits the paced design for "helping [her] grow confidence in [herself] and sharing [her] ideas" with others, something she "never would have even thought about doing before this class." The use of the positive term "grow" and declarative term "never" showcase that Student $\mathrm{N}$ benefits from the paced design beyond the scope of writing; she ultimately attributes her personal confidence and values were acknowledged and experimented within this paced process, expressing she is "so thankful for such an open environment."

\subsection{Spring Conclusions}

For the first round of workshops with Project 1, the results were varied in terms of the paced design although they were positive in their reflections of the workshop itself. It appeared as though students felt confident and comfortable from the start of the workshop process, students implementing rhetoric confidently in their work while comfortably discussing this with others. Students consistently offered positive reinforcement for their peers, instigating a positive dynamic for others while, by proxy, bolstering their confidence in their work and their ideas. Likewise, allowing for casual conversation on workshop materials was held in high regard for the participants, as they reported having scaffolded material helped their progress to the next stage without making the process overwhelming, namely with the Detailed Outlines and Rough Draft 1 .

As the Project 2 workshop process completed, similar results regarding confidence and the paced design emerged. Yet, in this round, the Rough Draft 1 seemed to be favored overall. Likewise, students seemed to explore their own personal identities given the vulnerability and personal connections the project prompt offers. In my observations, I noticed students being able 
to talk to one another more fluidly and comfortably — both in terms of the project itself as well as within casual conversation. Students began to articulate how meaningful being a part of a community of practice was to them in their reflections, with this articulation becoming clearer and more pronounced within the Project 3 reflections.

In the Project 3 reflections showcased the articulation of community, discourse, and practice more explicitly, with students beginning to make similar connections and find similar aspects meaningful. Students began to make articulations of why this paced design or collaboration was effective for them rather than simply stating that it was, indicating growth and confidence in articulation and discourse of practice had occurred. Again, the Detailed Outline served as most beneficial for students in this round of workshops.

The case studies furthered this growth and articulation of community and practice, showcasing the range of effectiveness the paced design had for the students. Their abilities to compare their previous and current academic experiences in relationship to the experiences they had in our course helped establish the growth, confidence, and efficacy of the workshop design in a variety of ways. With students crediting the workshop with making them feel more comfortable, confident, and prepared with writing reiterates that students can become a part of a community in practice and that, through a slower approach toward writing, students can grow not only as a writer but as a human, navigating the world of academia more comfortably and confidently. 


\section{Conclusion}

While the results were overwhelmingly positive for the workshop structure and the benefits it provided students, this does not dismiss the fact that these participants are only 15 of the 30 total students across both semesters, nor does the absence of negative feedback dismiss the fact that there are not any negative perceptions of the paced design, reflecting back on the Fall Case Study with Student G.

Yet, the positive feedback that did stem from the reflections and interviews showcased that the paced design was effective in that the participants were able to articulate the effectiveness of this paced design within their own terms and understandings. Most notably, the paced design appears to have eased anxieties not only in terms of writing but also in terms of being within academic spaces and interacting with the discourses that exist within these spaces. The case studies solidified the notion that students can benefit from this paced design in a variety of ways, wherein the paced design blends into many sectors of academia beyond writing an essay or collaborating with peers. If this study has demonstrated anything, it is that implementation of collaboration and simultaneous validation of differing writing processes through a slower approach toward writing are as crucial to the student learning process as they are in bolstering students' recognition of their role in academia. While this paced design is a start to this implementation in action, it can equally encourage an ease of anxiety that so frequently floods college students in their undergraduate years.

Implementing this paced design for one year has made clear to me that a workshop process is not so much claiming that one writing process is better than the other but, instead, 
acknowledging that students have varying writing processes and anxieties about writing. In the future, I hope to take what I learned in this study regarding confidence, classroom environment, and collaboration and reinforce this ease of anxiety by recognizing that each student learns differently. While the paced design earned positive feedback from participants, I am left with the consensus that providing opportunities for slower approaches to writing and simultaneously validating the differing writing processes is essential to highlight and emphasize within the classroom no matter the workshop design. Likewise, as Student O stated, the workshop design "[made] sure I did not just breeze through it so I could finish the assignment and move on, but rather made me stop and actually learn. I was more focused on learning than on getting a grade.” Thus, the paced design's ability to encourage "learning" about writing and the self rather than emphasize "getting a grade" reiterates the necessity of including a slower process toward writing to uplift these learning processes and simultaneously eliminate anxieties.

Ultimately, upon completing this study, I now aim to continue to create space in the classroom for these opportunities to occur-whether this is implementing the same paced design or not—as these opportunities undoubtedly prove beneficial and effective to students' comfort, personal growth, and writing approaches in a casual stress-free way, easing students' anxieties about their abilities to create as composition students. 


\section{WORKS CITED}

Bartholomae, David. "Inventing the University," Cross-Talk in Comp Theory.

Bazerman, Charles and Howard Tinberg. "Text is an Object Outside of Oneself that can be Improved and Developed" Naming What We Know: Threshold Concepts of Writing Studies. Ed. Linda Adler-Kassner and Elizabeth Wardle. University Press of Colorado, 2016.

Bruffee, Kenneth. "Collaborative Learning." College English, vol. 43, no. 7, 1981, pp. 745-747. JSTOR.

Bruffee, Kenneth A. "Collaborative Learning and the 'Conversation of Mankind."' College English, vol. 46, no. 7, 1984, pp. 635-652. JSTOR, www.jstor.org/stable/376924.

Burnham, Christopher. "Expressivist Pedagogy: Practice/Theory, Theory/Practice." A Guide to Composition Pedagogies, edited by Gary Tate, Amy Rupiper, and Kurt Schick, 2001.

Clark, Irene L. "Invention." Concepts in Composition: Theory and Practice in the Teaching of Writing. N.p., Taylor \& Francis, 2003.

Cooper, Marilyn. "The Ecology of Writing." College English. 48:4, April 1986. 364-375.

Dobrin, Sidney I. Postcomposition. Southern Illinois University Press, 2011.

Downs, Doug. "Revision is Central to Developing Writing." Naming What We Know: Threshold Concepts of Writing Studies. Ed. Linda Adler-Kassner and Elizabeth Wardle. University Press of Colorado, 2016. 
Elbow, Peter. Writing Without Teachers. Oxford University Press, 1998.

Harris, Muriel. "Collaboration is Not Collaboration Is Not Collaboration: Writing Center

Tutorials vs. Peer-Response Groups." College Composition and Communication. Vol. 43, No. 3 (Oct. 1992): 369-383.

Howard, Rebecca Moore. "Collaborative Learning." A Guide to Composition Pedagogies, edited by Gary Tate, Amy Rupiper, and Kurt Schick, 2001.

Lamott, Anne. "Shitty First Drafts." Language Awareness: Readings for College Writers. Ed. by Paul Eschholz, Alfred Rosa, and Virginia Clark. 9th ed. Boston: Bedford/St. Martin's, 2005: 93-96.

Lynn, Steven. Rhetoric and Composition: An Introduction. Cambridge University Press, 2010. Print.

Martorana, Christine. "Through the Lens of Figured Worlds: A Heuristic for Productive Collaboration." Composition Studies, vol. 45, no. 1, Spring 2017, pp. 59-73. EBSCOhost, search.ebscohost.com/login.aspx?direct=true\&AuthType=ip,uid,cookie,url\&db=aph\&AN $=122682272 \&$ site $=$ ehost-live

Oleksiak, Timothy. “A Queer Praxis for Peer Review” College Composition and Communication Vol. 72, No. 2, 2020, https://library.ncte.org/journals/ccc/issues/v72-2/31039 
Olson, Gary A. "Toward a Post-Process Composition:Abandoning the Rhetoric of Assertion." Post-Process Theory: Beyond the Writing-Process Paradigm. Southern Illinois University Press, 1999.

Roozen, Kevin. "Writing is a Social and Rhetorical Activity." Naming What We Know: Threshold Concepts of Writing Studies. Ed. Linda Adler-Kassner and Elizabeth Wardle. University Press of Colorado, 2016.

Roozen, Kevin. "Writing is Linked to Identity." Naming What We Know: Threshold Concepts of Writing Studies. Ed. Linda Adler-Kassner and Elizabeth Wardle. University Press of Colorado, 2016.

Shaffer, David Williams. "Models of Situated Action: Computer Games and the Problem of Transfer" N.p., n.d. PDF.

Shipka, Jody. "Beyond Text and Talk: A Multimodal Approach to First-Year Composition." First-Year Composition From Theory to Practice. Ed. Deborah Coxwell-Teague and Ronald F. Lunsford. Parlor Press, 2014.

Tinberg, Howard. "Working Through Theory in a Community College Composition Classroom" First-Year Composition From Theory to Practice. Ed. Deborah Coxwell-Teague and Ronald F. Lunsford. Parlor Press, 2014.

Tinberg, Howard. "Metacognition is not Cognition" Naming What We Know: Threshold Concepts of Writing Studies. Ed. Linda Adler-Kassner and Elizabeth Wardle. University Press of Colorado, 2016. 
Tobin, Lad. "Process Pedagogy." A Guide to Composition Pedagogies, edited by Gary Tate, Amy Rupiper, and Kurt Schick, 2001.

Trimbur, John. "Consensus and Difference in Collaborative Learning." College English, vol. 51, no. 6, 1989, pp. 602-616. JSTOR, www.jstor.org/stable/377955.

"Workshop." Keywords in Creative Writing, by WENDY BISHOP and DAVID STARKEY, University Press of Colorado, 2006, pp. 197-200. JSTOR, www.jstor.org/stable/j.ctt4cgr61.44. 


\section{Appendices}

\section{Appendix A. (Timeline):}

The timeline for my methods is as follows:

I. Recruit participants

A. I recruited participants as soon as I received IRB approval in October for the Fall 2020 semester. In Spring 2021, I recruited participants in week two of the semester. In Fall 2020, there were seven participants of this study. In Spring 2021, there were eight participants of this study. All were over the age of 18 .

II. Workshop observations

A. I observed participants on Zoom weekly, noting any coding-related observations or terminology as well as general observations. Data was collected and analyzed weekly.

III. Collect workshop reflections

A. Workshop reflections (see Appendix C) were completed after each workshop on Canvas. I collected the data once all were submitted and analyzed them soon after.

IV. Interviews

A. Interviews were conducted in April of 2021. The interviews were not audio or video recorded. I took handwritten notes, transcribing and summarizing the participant's answers to the questions asked (see appendix). 
V. Discourse analysis

A. I gathered the data collected throughout the semester and coded it using the coding methods. I used rubrics (see appendix) as a means of quantitative measure to determine the level of understanding regarding various concepts as a base line. I then evaluated and observed the qualitative data, which this study relies on primarily, and analyzed these further. 


\section{Appendix B. (Rubrics):}

Writing/Rhetoric

\begin{tabular}{|c|c|c|}
\hline Beginner Level & Intermediate Level & Mastery Level \\
\hline $\begin{array}{l}\text { Students shows some } \\
\text { awareness of writing and } \\
\text { rhetorical strategies with few } \\
\text { misunderstanding/errors; } \\
\text { student has some } \\
\text { sophistication in sources used; } \\
\text { work has some structure, } \\
\text { needs more organization but } \\
\text { does not impede } \\
\text { understanding; work indicates } \\
\text { beginning level of } \\
\text { understanding rhetorical } \\
\text { strategies, student could } \\
\text { develop a deeper } \\
\text { understanding of rhetoric }\end{array}$ & $\begin{array}{l}\text { Students shows adequate } \\
\text { awareness of writing and } \\
\text { rhetorical strategies; student } \\
\text { has decent sophistication and } \\
\text { use of sources used; work has } \\
\text { mostly a logical structure and } \\
\text { organization; work indicates } \\
\text { average use and understanding } \\
\text { of rhetorical strategies }\end{array}$ & $\begin{array}{l}\text { Students shows strong } \\
\text { awareness of writing and } \\
\text { rhetorical strategies; student } \\
\text { has strong sophistication and } \\
\text { use of sources used; work has } \\
\text { logical structure; work has } \\
\text { effective use of rhetorical } \\
\text { strategies; student displays } \\
\text { strong understanding of } \\
\text { rhetoric throughout the } \\
\text { projects }\end{array}$ \\
\hline
\end{tabular}

Confidence and Growth in Writing

\begin{tabular}{|l|l|l|}
\hline Beginner Level & Intermediate Level & \multicolumn{1}{|c|}{ Mastery Level } \\
\hline $\begin{array}{l}\text { Student suggests they have } \\
\text { had increased confidence in } \\
\text { writing through reflections yet } \\
\text { does not state this directly; } \\
\text { student displays some }\end{array}$ & $\begin{array}{l}\text { Student implies they have had } \\
\text { increased confidence in } \\
\text { studing through reflections; displays decent } \\
\text { metacognitive awareness of }\end{array}$ & $\begin{array}{l}\text { Student directly states they } \\
\text { have had increased confidence } \\
\text { in writing through reflections; } \\
\text { student displays } \\
\text { metacognitive awareness of }\end{array}$ \\
\hline
\end{tabular}




\begin{tabular}{|c|c|c|}
\hline $\begin{array}{l}\text { metacognitive awareness of } \\
\text { writing choices in the } \\
\text { reflections; student is able to } \\
\text { recognize their growth as a } \\
\text { writer throughout the semester } \\
\text { but articulates this growth } \\
\text { minimally (not offering much } \\
\text { metacognition on their } \\
\text { process); student shows some } \\
\text { confidence in their writing } \\
\text { choices, assertion of } \\
\text { opinion/points, discourse in } \\
\text { the community yet } \\
\text { voices/shows their hesitance } \\
\text { in fully embracing their } \\
\text { interests/beliefs/values in their } \\
\text { writing; some revisions made } \\
\text { to work throughout workshop } \\
\text { process show strong } \\
\text { development of understanding } \\
\text { and benefit the work and } \\
\text { improved understanding of the } \\
\text { prompt }\end{array}$ & $\begin{array}{l}\text { writing choices in the } \\
\text { reflections; student is able to } \\
\text { recognize and articulate their } \\
\text { growth as a writer throughout } \\
\text { the semester; student shows } \\
\text { confidence in their writing } \\
\text { choices, assertion of } \\
\text { opinion/points, discourse in } \\
\text { the community yet shows } \\
\text { some hesitance in fully } \\
\text { embracing their } \\
\text { interests/beliefs/values in their } \\
\text { writing; revisions made to } \\
\text { work throughout workshop } \\
\text { process show decent } \\
\text { development and } \\
\text { understanding; student shows } \\
\text { an understanding of the } \\
\text { prompt and revisions made } \\
\text { were related to the prompt and } \\
\text { did not diminish } \\
\text { understanding of the work }\end{array}$ & $\begin{array}{l}\text { writing choices in the } \\
\text { reflections; student is able to } \\
\text { recognize and articulate their } \\
\text { growth as a writer throughout } \\
\text { the semester; student shows } \\
\text { increased confidence in their } \\
\text { writing choices, assertion of } \\
\text { opinion/points, discourse in } \\
\text { the community; shows } \\
\text { comfort in discussing their } \\
\text { interests/beliefs/values in their } \\
\text { writing; revisions made to } \\
\text { work throughout workshop } \\
\text { process show strong } \\
\text { development of understanding } \\
\text { and benefit the work; student } \\
\text { shows firm understanding of } \\
\text { the prompt and revisions made } \\
\text { were cohesive to the prompt }\end{array}$ \\
\hline
\end{tabular}

Writer Identity

\begin{tabular}{|c|c|c|}
\hline Beginner Level & Intermediate Level & Mastery Level \\
\hline $\begin{array}{l}\text { Student has began to develop a } \\
\text { "voice" in their writing yet } \\
\text { tries to write directly for the } \\
\text { instructor (not the audience of } \\
\text { project or for themselves); } \\
\text { student feels somewhat } \\
\text { comfortable to share their } \\
\text { beliefs/values/opinions in } \\
\text { writing yet shows hesitation in } \\
\text { expressing this; student }\end{array}$ & $\begin{array}{l}\text { Student has developed a } \\
\text { "voice" in their writing; } \\
\text { student feels somewhat } \\
\text { comfortable to share their } \\
\text { beliefs/values/opinions in } \\
\text { writing; student acknowledges } \\
\text { in reflection that workshop } \\
\text { assisted in developing their } \\
\text { "identity"; student includes in } \\
\text { their work direct ties/interests }\end{array}$ & $\begin{array}{l}\text { Student has developed a } \\
\text { "voice" in their writing; } \\
\text { student feels comfortable to } \\
\text { share } \\
\text { beliefs/values/opinions their } \\
\text { writing; student acknowledges } \\
\text { in reflection that workshop } \\
\text { assisted in developing their } \\
\text { "identity"; student includes in } \\
\text { their work direct ties/interests }\end{array}$ \\
\hline
\end{tabular}




\begin{tabular}{|l|l|l|l|}
\hline acknowledges in reflection & to their own personal identity & to their own personal identity \\
that workshop assisted in & (such as gender, ethnicity, & (such as gender, ethnicity, \\
developing their "identity" but & etc.) occasionally; student & etc.); student shows in their \\
does not specify how; student & shows in their reflection & reflection answers that they \\
starts to include in their work & answers that they were & were comfortable and able to \\
direct ties/interests to their & comfortable to discuss their & include information regarding \\
own personal identity (such as & own beliefs/values and & their personal identity that, in \\
gender, ethnicity, etc.); & included some & turn, allowed for development \\
student shows in their & information/correlation to & of their individualized writer \\
reflection answers that they & their personal identity that, in & identity \\
were somewhat comfortable & turn, allowed for development & \\
to discuss their own & of their individualized writer & \\
beliefs/values and included & identity & \\
some information/correlation & & \\
to their personal identity; & & \\
development of their & & \\
individualized writer identity & & \\
is in development but needs & & \\
more & &
\end{tabular}

Workshop

\begin{tabular}{|c|c|c|}
\hline Level & Intermediate Level & Mastery Level \\
\hline $\begin{array}{l}\text { Student was sometimes } \\
\text { engaging with others and } \\
\text { collaboratively discussing } \\
\text { their work in the Zoom } \\
\text { workshops; student shows } \\
\text { some levels of engagement } \\
\text { with the prompt; student gave } \\
\text { some helpful feedback to } \\
\text { peers during asynchronous } \\
\text { workshop; student reflection } \\
\text { indicates workshop feedback } \\
\text { was helpful/was sometimes } \\
\text { helpful; student work } \\
\text { indicates some changes were }\end{array}$ & $\begin{array}{l}\text { Student was mostly engaging } \\
\text { with others } \\
\text { collaboratively discussing } \\
\text { their work in the Zoom } \\
\text { workshops; student shows } \\
\text { decent levels of engagement } \\
\text { with the prompt; student gave } \\
\text { mostly helpful feedback to } \\
\text { peers during asynchronous } \\
\text { workshop; student reflection } \\
\text { indicates workshop feedback } \\
\text { was helpful and constructive; } \\
\text { student work indicates some } \\
\text { changes were made based on }\end{array}$ & $\begin{array}{l}\text { Student was engaging with } \\
\text { others and collaboratively } \\
\text { discussing their work in the } \\
\text { Zoom workshops; student } \\
\text { shows stronger levels of } \\
\text { engagement with the prompt; } \\
\text { student gave helpful feedback } \\
\text { to peers during asynchronous } \\
\text { workshop; student reflection } \\
\text { indicates workshop feedback } \\
\text { was helpful and constructive; } \\
\text { student work indicates } \\
\text { changes were made based on } \\
\text { feedback given; changes made }\end{array}$ \\
\hline
\end{tabular}




\begin{tabular}{|l|l|l|}
\hline made based on feedback & $\begin{array}{l}\text { feedback given; changes made } \\
\text { given; some changes made to } \\
\text { to work were mostly } \\
\text { work were mostly beneficial } \\
\text { beneficial to make with some } \\
\text { to make with some } \\
\text { redundancies }\end{array}$ & $\begin{array}{l}\text { redundancies } \\
\text { relevant to make }\end{array}$ \\
\hline
\end{tabular}




\section{Appendix C. (Workshop Reflection Prompts).}

1. (Project 1-3 reflection) Answer the following questions to the best of your ability:

1. What was most beneficial to you regarding the workshop process for this project? Why?

2. What rhetorical strategies or writing techniques did you use in this project? What did you learn by using them?

3. How confident do you feel to use these strategies again in the future (either in future project(s)/writing(s) for this course or future courses)?

4. What day of the workshop was most helpful to you in terms of receiving peer feedback?

5. What day of workshop was most helpful to you in terms of the workshop material ("Idea Document," "Detailed Outline," "Rough Draft 1")? What material helped you think the most thoroughly about your ideas, plans, and writing? Why?

6. How has the workshop for this project made you think about your own choices and authorial "voice"? Did your project ideas/topics stem from your own interests/values?

Did you feel comfortable writing about these ideas/topics?

7. How did the workshop as a whole affect your understanding of the project, writing styles, and rhetorical effectiveness?

8. Make any final comments or feedback regarding the feedback for this workshop.

2. (Collective Workshop reflection) Answer the following questions to the best of your ability: 
1. What was most beneficial to you regarding the workshop as a whole and why?

2. What rhetorical strategies or writing techniques did you tend to use the most? What did you learn by using them?

3. How did workshop affect your confidence in your writing? Do you feel your writing has improved since the start of the semester?

4. What day of the workshop was most helpful to you in terms of receiving peer feedback?

5. How has the workshop process made you think about your writing choices and authorial "voice"? Did your project ideas/topics stem from your own interests/values? Did you feel comfortable writing about these ideas/topics?

6. What day of workshop was most helpful to you in terms of the workshop material ("Idea Document," "Detailed Outline," "Rough Draft 1")? What material helped you think the most thoroughly about your ideas, plans, and writing? Why?

7. How did the workshop as a whole affect your understanding of the project, writing styles, and rhetorical effectiveness?

8. Make any final comments or feedback regarding the feedback for this workshop. 


\title{
Appendix D. (Fall Results)
}

\author{
Case Study 1: Student A and Student B with Project 1
}

Student A is first-year student majoring in Business Administration. Student A's first project was an advertisement about engaged species and poaching; his second project was an interview with his roommate about their experiences and education about environmental issues; and his third project was researching company marketing incentives and greenwashing. Student A chose to revise his second and third projects for the final portfolio. Student B is a first-year Political Science major. Her first project was a series of poems about California wildfires; her second project was an interview with her close friend about educational awareness and environmental activism; and her third project covered research on deforestation. Student B chose to revise project 2 and project 3 for the final portfolio. This case study examines the ways Student A and Student B's project 1 changed through the course of the workshop materials and how the Rough Draft 2 displayed effective rhetorical strategies.

\section{Student A}

Given project 1 was the first introduction to implementing rhetoric themselves, there were some expectations that students may be hesitant or fearful to explore rhetorical effectiveness visually rather than analytically — as is often the case in high school with analysis of ethos, pathos, and logos. Student A and Student B both chose to not revise their project 1 for the final portfolio, and when in individual conferences with me about their portfolio, both claimed they were confident with the work they produced and would rather revise something written. 
Student A's reflection of project 1 states he "used a lot of visual rhetoric to push a call to action and a sense of a lack of hope. By using these strategies, I learned the significance of rhetorical techniques and what effect they can add to the audiences [sic] opinion." When returning to Student A's Idea Document for this project, Student A initially plans to create an advertisement "about helping endangered species and raising awareness for the reasons they are becoming extinct." In terms of rhetorical choices, Student A wants to "invoke a sense of urgency in the audience while also displaying an innocent look on the faces of these animals. I plan on using bold lettering to really make a lasting impression, and use colors like red and orange to display this... [with] gray and black in the backgrounds of the animals to show a gloomy future if we don't act now. In either the top or bottom I will use a lighter color to show a small sense of hope." Color is further described in Student A's Detailed Outline, stating "the colors will play an integral part in my advertisement. I want it to look gloomy and dark within the faces of the animals." Student A submitted the following as his Rough Draft 1:

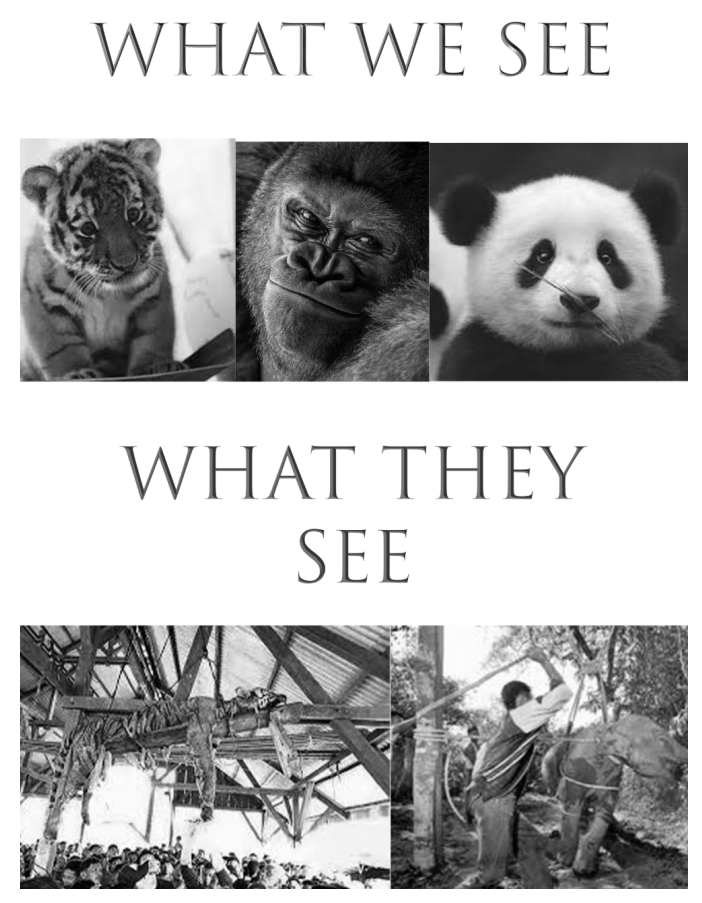


Despite the advice of peers within the written and verbal peer feedback during the Rough Draft 1 workshop about the importance of incorporating color, Student A submitted the above piece for his Rough Draft 2 as well. As self-stated in his discourse generators (questions or comments for his peers for workshop), the student experimented with Photoshop for the first time and applied a black and white gradient over the originally colorful images. He later confessed to me in an individual conference that Photoshop was time consuming and difficult to understand, thus he was unable to truly get the effect and produce the image he originally imagined within his Idea Document. It is because of this that Student A was dissuaded to revise project 1 for the portfolio.

Did Student A's use of visual rhetoric suffer due to the difficulty of the software used? Was advice given in workshop inhibiting the original plan to be followed through, or did workshop inspire the black and white idea, yet the ability to include color was forgoed due to the software? Was this because of the nature of the project (multimodal, first project) that Student A had difficulty? Highlighted below is a quantitative measurement of Student A's level of understanding with writing and rhetoric:

\begin{tabular}{|c|c|c|}
\hline Beginner Level & Intermediate Level & Mastery Level \\
\hline $\begin{array}{l}\text { Students shows some } \\
\text { awareness of writing and } \\
\text { rhetorical strategies with few } \\
\text { misunderstanding/errors; } \\
\text { student has some } \\
\text { sophistication in sources used; } \\
\text { work has some structure, } \\
\text { needs more organization but } \\
\text { does not impede } \\
\text { understanding; work indicates } \\
\text { beginning level of } \\
\text { understanding rhetorical }\end{array}$ & $\begin{array}{l}\text { Students shows adequate } \\
\text { awareness of writing and } \\
\text { rhetorical strategies; student } \\
\text { has decent sophistication and } \\
\text { use of sources used; work has } \\
\text { mostly a logical structure and } \\
\text { organization; work indicates } \\
\text { average use and understanding } \\
\text { of rhetorical strategies }\end{array}$ & $\begin{array}{l}\text { Students shows strong } \\
\text { awareness of writing and } \\
\text { rhetorical strategies; student } \\
\text { has strong sophistication and } \\
\text { use of sources used; work has } \\
\text { logical structure; work has } \\
\text { effective use of rhetorical } \\
\text { strategies; student displays } \\
\text { strong understanding of } \\
\text { rhetoric throughout the } \\
\text { projects }\end{array}$ \\
\hline
\end{tabular}




\begin{tabular}{|l|l|l|}
\hline $\begin{array}{l}\text { strategies, student could } \\
\text { develop a deeper } \\
\text { understanding of rhetoric }\end{array}$ & \\
\hline
\end{tabular}

I am hesitant to consider Student A as "intermediate" within this project as he had a firm use and understanding of the rhetorical strategies when discussed in his workshop materials, yet did not display these strategies visually to their fullest extent. I will say that Student A did not make "errors" in choosing the rhetorical strategies, more so that they were lacking in the draft. As mentioned in the questions prior to the rubric, I am aware that there are many potential factors as to why this student showcases a beginner level of rhetoric in the project 1 ; these external factors are issues that I need to explore more deeply next semester.

\section{Student B}

Both Student A and Student B originally intended to have a sense of hope incorporated into their creative portrayal of the environment. Student B took a similar creative approach for Project 1 hoping to instill hope in the audience, her poem about wildfires incorporates color in both rough drafts, following the original plan discussed in her Idea Document more closely than Student A. As mentioned in her Idea Document, "I want this poem to be realistic and have a more sad undertone in the beginning (using fear and directness to get the urgency of the point across) and then to transition to a more hopeful tone in the ending of the poem." In the Detailed Outline, Student B writes "Visual rhetoric will be present through the use of red text (since red is usually associated with urgency/danger and passionate messages) and in a longer line break between the 
hopeful and hopeless sections of the poem for emphasis and to allow the audience to have a moment of reflection before learning how they can help/address climate change/wildfires." Student B submitted the following for her Rough Draft 1:

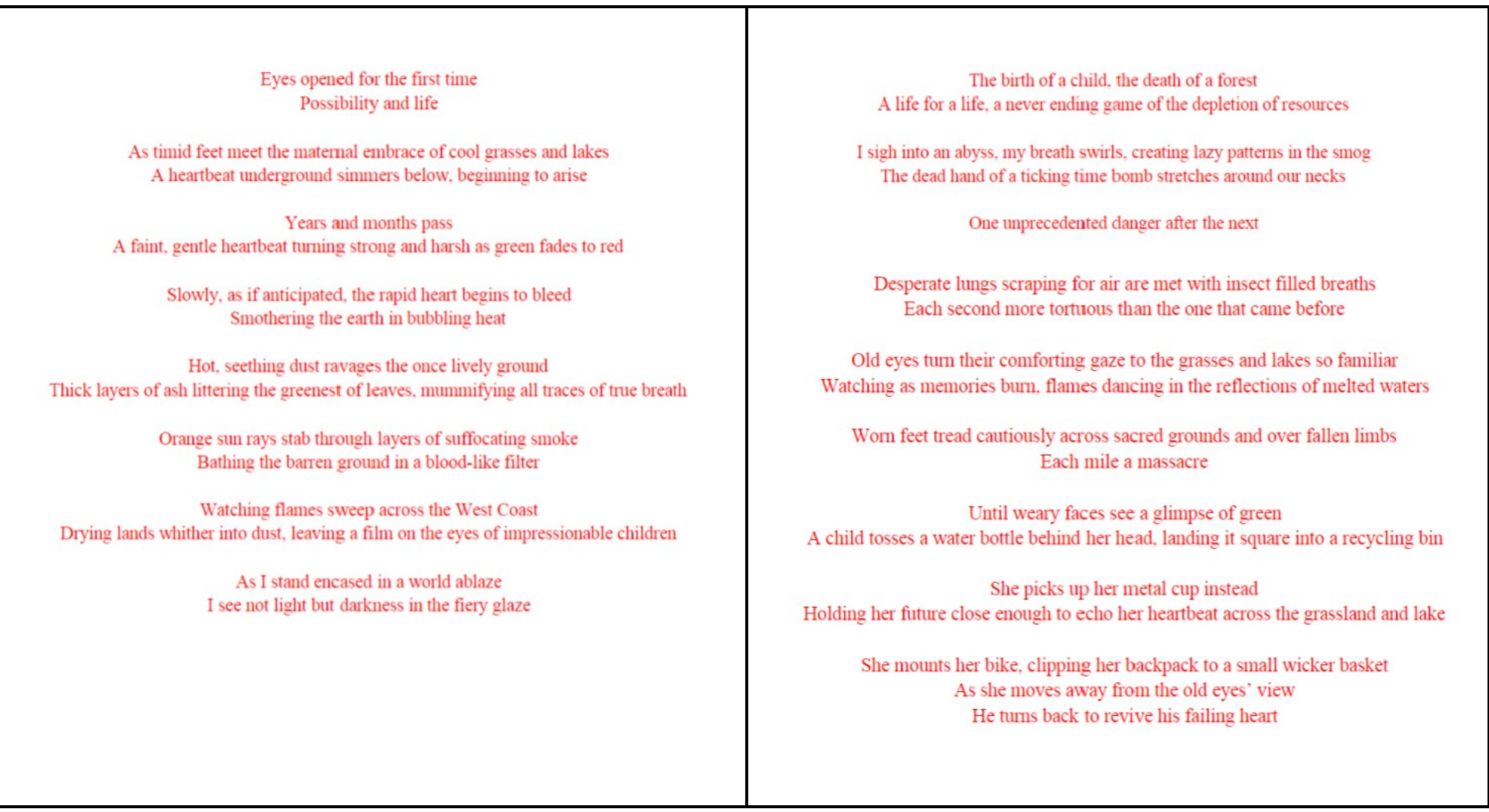

Student B made revisions based on workshop and submitted the following for Rough Draft 2: 


\section{Counting Heartbeats}

Eyes open for the first time

Possibility and life exuding from cool surroundings

As timid feet meet the maternal embrace of cool grasses and lakes

A heartbeat underground simmers below, beginning to arise

Months and years pass

A faint, gentle heartbeat turning strong and harsh as green fades to red

Slowly, as if anticipated, the rapid heart begins to bleed

Smothering the earth in bubbling heat

Hot, seething dust ravages the once lively ground

Thick layers of ash littering the greenest of leaves, mummifying all traces of true breath

Orange sun rays stab through layers of suffocating smoke

Bathing the barren ground in a blood-like filter

Watching flames sweep across the West Coast

Drying lands whither into dust, leaving a film on the eyes of impressionable children

As I stand encased in a world ablaze

I see not light but darkness in the fiery glaze

The birth of a child, the death of a forest

A life for a life, a never ending game of the depletion of resources

I sigh into an abyss, my breath swirls, creating lazy patterns in the smog

The dead hand of a ticking time bomb stretches around our necks

One unprecedented danger after the next

Fear that makes the heart skip a beat
Desperate lungs scraping for air are met with insect filled breaths

Each second more tortuous than the one that came before

Paw prints fade into indifference

The final remains of their great escape

Bleary cat-like eyes turn towards the sky

A primal prayer for salvation

A distant cry echoes off of charcoaled bushes

Water-deprived animals search for vitality in a sea of neverending dust

Human hands encase the struggling bodies of animals far from home

A mutual understanding passes through, no one is safe

Old eyes turn their comforting gaze to the grasses and lakes so familiar Watching as memories burn, flames dancing in the reflections of melted waters

Worn feet tread cautiously across sacred grounds and over fallen limbs Each mile a massacre

Until weary faces see a glimpse of green

A child tosses a water bottle behind her head, landing it square into a recycling bin

She picks up her metal cup instead

Holding her future close enough to echo her steady heartbeat across grasslands and lakes

She mounts her bike, clipping her backpack to a small wicker basket

As she moves away from the old eyes' view

He turns back to revive his failing heart

When looking at Student A and Student B's Rough Draft 2, Student B maintains her

original ideas and follows through with the intended message. While Student B maintains the intended message and ideas prefaced in her Idea Document, this not does mean that Student A's work is "bad." Student A does not rely on the visual rhetorical role of color that originally was meant to inspire hope, and while the ideas are subject to change through the course of workshop, what was interesting is that Student A asked in his discourse generator for the last day of workshop 
"Is there any different colors I could incorporate to add to the rhetorical strategies?" This discourse generator shows that Student A is aware of and considering the role that color plays within his piece, and is still mindful of his originally intended message.

While visual rhetoric is just one aspect of writing and rhetoric, it appears that Student B's originally intended message of hope was maintained within the content of her poem rather than color, the color red instead highlighting the urgency to act upon this hopefulness indicated in the second half of her poem. Student A intended to use color to provide a sense of "hope" and highlight the "innocence" of the animals, yet did not incorporate that into his draft. Whether or not this original plan was maintained throughout workshop is not as crucial, yet it is important to consider whether workshop allowed for the student to think critically about their rhetorical and writing choices and whether these choices strengthened the end result. Student B reflects on this in her workshop reflection post, stating "I used linear genre (which helped me to better understand the necessity of making concepts easy to understand for a broad audience), imagery (which allowed me to reflect on what would be more effective to my audience), visual choices (which prompted me to consider more in-depth how choices as seemingly small as font color have great effect on the perception of a piece), and appeals to emotion and logic (which gave me the opportunity to reflect on how persuasion is used even in a story-telling or fact-ridden visual format)." Student B was able to clearly and thoughtfully articulate the rhetorical choices she made and how these affected her project and her knowledge of rhetorical significance. This level of reflection indicates that the rhetorical skills were present in the early stages of the project and were continually referenced throughout the completion of the project.

Student B stuck to her original rhetorical outline, yet does this warrant higher sophistication and knowledge of rhetorical skills? Did Student B have prior knowledge of poetry and creative 
writing, hence why she was able to display rhetorical significance within her writing more easily? Highlighted below is a quantitative measurement of Student B's level of understanding with writing and rhetoric:

\begin{tabular}{|c|c|c|}
\hline Beginner Level & Intermediate Level & Mastery Level \\
\hline $\begin{array}{l}\text { Students shows some } \\
\text { awareness of writing and } \\
\text { rhetorical strategies with few } \\
\text { misunderstanding/errors; } \\
\text { student has some } \\
\text { sophistication in sources used; } \\
\text { work has some structure, } \\
\text { needs more organization but } \\
\text { does not impede } \\
\text { understanding; work indicates } \\
\text { beginning level of } \\
\text { understanding rhetorical } \\
\text { strategies, student could } \\
\text { develop a deeper } \\
\text { understanding of rhetoric }\end{array}$ & $\begin{array}{l}\text { Students shows adequate } \\
\text { awareness of writing and } \\
\text { rhetorical strategies; student } \\
\text { has decent sophistication and } \\
\text { use of sources used; work has } \\
\text { mostly a logical structure and } \\
\text { organization; work indicates } \\
\text { average use and understanding } \\
\text { of rhetorical strategies }\end{array}$ & $\begin{array}{l}\text { Students shows strong } \\
\text { awareness of writing and } \\
\text { rhetorical strategies; student } \\
\text { has strong sophistication and } \\
\text { use of sources used; work has } \\
\text { logical structure; work has } \\
\text { effective use of rhetorical } \\
\text { strategies; student displays } \\
\text { strong understanding of } \\
\text { rhetoric throughout the project }\end{array}$ \\
\hline
\end{tabular}

Student B was able to use genre conventions of poetry (metaphor, diction, line breaks, rhyme scheme, etc.) while showcasing rhetorical power of color both within the content and design of the poem. Yet, as questioned earlier, to what extent does prior knowledge, comfortability, and experience with creative writing or projects factor into this level of awareness of writing and rhetoric? This is a concept I aim to explore more deeply next semester.

Case Study 2: Student D and Student F with Project 3 
Student D is a first-year undeclared major. Student D's first project was a painting showcasing the before and after of greenhouse gas effects; her second project was an interview with her roommate about vegetarianism, activism, and geographical location; her third project was research on fast fashion. Student D chose to revise projects 2 and 3 for the portfolio. Student F is a first-year Integrated Education major. Student F's first project was a sea turtle sculpture out of trash; her second project was an interview with her dad about his activism, youth, and parenting in connection to his environmental passion; her third project was research on fast fashion. Student F chose to revise projects 1 and 3 for her portfolio. This case study will examine the effectiveness of writing and rhetorical skills (specifically with sources, organization, and consideration of rhetoric) using Student D and Student F's project 3 on the same subject: fast fashion.

\section{Student $D$}

Student $\mathrm{D}$ writes in her Idea Document that she wanted to explore trends of fashion in relation to social media, examining why "many companies have multiple fashion weeks rather than a few seasonal ones in the year. The clothes now produced are often made with cheaper materials and done through work that fails to properly compensate workers and impacts the environment." Student D expands on this in her Detailed Outline, planning to incorporate greenwashing - a topic we discussed early on in the semester to evaluate visual rhetorical significance - and making a greenwashing case study analysis with brands H\&M and Reformation. For the initial organization of the paper, Student D outlines the following: 
I. Explain what fast fashion is and the negative effects, such as the poor treatment of workers and impacts on the environment.

A. I will put the information from my source about the Rana Plaza collapse here (source 4)

B. I will also find more sources about the negative impacts on the environment from fast fashion.

II. Discuss greenwashing (what it is, why companies use it, and how consumers can know).

III. Explain how trends influence consumers and manufacturers. (Im not sure if I should keep this one, but I think that it definitely applies to fast fashion)

IV. Compare two companies - H\&M and reformation

A. For this section I plan to show any differences in the companies' transparency with sustainability, show differences in the costs spent by looking at financial reports (for materials in clothing, manufacturing, advertising, etc) and analyze these costs, and look at any greenwashing or general differences between the companies.

V. I will then address potential solutions of fast fashion.

Her submission of Rough Draft 1 follows this originally outlined structure closely, while her Rough Draft 2 submission makes some changes: moving the trends and advertising paragraph before the greenwashing paragraph, greatly elaborating on the H\&M and Reformation case studies, yet keeps the solution paragraph the same. Interestingly, the restructuring of the trends paragraph was not a discourse generator that Student D asked for workshop. While this may have been discussed beyond the discourse generators, this paragraph movement proved beneficial to the overall structure of the piece.

In terms of sources used, Student D incorporated a variety of scholarly journal articles and magazine articles, with a primary source being H\&M's website within the rhetorical analysis. Student D incorporated quotes sufficiently with an occasional floating quote appearing, yet overall the quotes and paraphrases chosen enhanced the argument well. Student D's rhetorical analysis of the H\&M site details the role of greenwashing through diction, visuals, colors, and advertising efforts. Below is an excerpt: 


\begin{abstract}
asked, to which they answer "We're getting there" (H\&M). For a customer who wants to find a
brand they think is sustainable, and not have to do a lot of research, H\&M looks like the perfect

candidate. They have begun to appear to be more transparent, which is more than other fast

fashion companies, but there are still areas in which they can improve. In 2016, H\&M used a

greenwashing campaign stating that their company will be recycling clothes by using them in

new clothes. This is contradictory when examining the company's manufacturing practices,

because they produce a large amount of clothing. Their clothing production impacts the

environment through shipping, dyes in clothing, and consumption of resources. Their campaign,

which states that they will use 1,000 pounds of recycled clothes, will take years to become a

reality and produce new clothes using the old ones, while in truth they produce that same amount

of clothes within days. H\&M has also presented their plan to reduce their greenhouse gas

emissions by the year 2030. H\&M is not the only company to do this. Many companies make a

point of saying that they will be sustainable in a certain number of years; but what prevents them

from being sustainable sooner or now? Likely, the answer is related to the desire to generate a

higher profit. As a whole, H\&M operates under an unsustainable business model, because

regardless of any promises of future endeavors, they still produce "cheap, easily disposable

clothing" (Bain). The company Reformation uses more sustainable practices. Similar to H\&M,
\end{abstract}

While more analysis could have been done for the Rough Draft 2, Student D showcases an understanding of rhetorical effectiveness and is evaluating it in the context of fast fashion advertising. Student D showcased a firm knowledge of various strategies and how they can be used within her project, such as research, statistics, case studies, and rhetorical analysis, organizing these in a coherent way. Highlighted below is a quantitative measurement of Student D's level of understanding with writing and rhetoric:

\begin{tabular}{|c|l|l|}
\hline Beginner Level & \multicolumn{1}{|c|}{ Intermediate Level } & \multicolumn{1}{|c|}{ Mastery Level } \\
\hline $\begin{array}{l}\text { Students shows some } \\
\text { awareness of writing and } \\
\text { rhetorical strategies with few } \\
\text { misunderstanding/errors; } \\
\text { student has some } \\
\text { sophistication in sources used; }\end{array}$ & $\begin{array}{l}\text { Students shows adequate } \\
\text { awarens of writing and } \\
\text { rhetorical strategies; student } \\
\text { has decent sophistication and } \\
\text { use of sources used; work has } \\
\text { mostly a logical structure and }\end{array}$ & $\begin{array}{l}\text { Students shows strong } \\
\text { awareness of writing and } \\
\text { retorical strategies; student } \\
\text { has strong sophistication and } \\
\text { use of sources used; work has } \\
\text { logical structure; work has }\end{array}$ \\
\hline
\end{tabular}




\begin{tabular}{|c|c|c|}
\hline $\begin{array}{l}\text { work has some structure, } \\
\text { needs more organization but } \\
\text { does not impede } \\
\text { understanding; work indicates } \\
\text { beginning level of } \\
\text { understanding ratorical } \\
\text { strategies, student could } \\
\text { develop a deeper } \\
\text { understanding of rhetoric }\end{array}$ & $\begin{array}{l}\text { organization; work indicates } \\
\text { average use and understanding } \\
\text { of rhetorical strategies }\end{array}$ & $\begin{array}{l}\text { effective use of rhetorical } \\
\text { strategies; student displays } \\
\text { strong understanding of } \\
\text { rhetoric throughout the project }\end{array}$ \\
\hline
\end{tabular}

It is clear that Student D thoughtfully understood the role organization plays in a piece, choosing sources that can be most applicable to the audience she is trying to reach. As self-stated in the project 3 and collective workshop reflection, Student D used "logos through facts and pathos through a specific example of people who were affected... I think that having an audience in mind helped me write using techniques that I thought would be effective for them, and in that way I also learned how to write for a specific audience." While the third project was arguably the most difficult of three given, Student D was able to incorporate difficult concepts of rhetorical analyses, yet more development on these analyses as well as more elaboration on the sources used would have proven beneficial to incorporate.

\section{Student F}

Student F takes a similar approach to Student D, yet does not emphasize marketing and greenwashing as much but instead focuses on environmental awareness and evaluating "slow fashion," or honestly sustainable, brands in conjunction with fast fashion brands like H\&M. Student F writes in her Idea Document that her initial idea is "to research about fast fashion and its impact on the environment. I would like to specifically focus on America and our impact on 
their environment through fast fashion and how brands are responding to an increase in environmental awareness." In her Detailed Outline, she outlines the potential organization of her project as:

Organization

- I want to first talk about the environmental impact of fast fashion. In this paragraph I will make sure to reference studies, specific information/facts about fast fashion. I will talk about both the US and other countries

- Then I want to talk about the rise of "slow fashion" brands, sustainable lines from brands, the rise in thrifting/depop, etc. Since I talked about other countries in my last paragraph I want to see if there is any information on sustainable fashion brands from these other countries.

- Finally, I want to talk about possible solutions. I want to make sure to mention how there isn't just one clear solution to fast fashion as many "solutions" have their pros/cons.

Student F maintains this structure in her Rough Draft 1, yet adds more content on greenwashing and the role of social media, like TikTok, in regards to slow and fast fashion awareness and marketing. In her Rough Draft 2, Student F dedicates an entire paragraph to slow and fast fashion representation on TikTok, which ties in well the discussion of the two types of fashion while offering an opportunity for rhetorical analysis: 
While slow fashion is on the rise, the industry is facing stiff competition from fast fashion brands and their hold on social media apps, namely TikTok. Major fast fashion brands like H\&M, Pretty Little Thing, and Boohoo have major followings on the app. Brands like Blush Mark have even used TikTok influencers to advertise for their brands, with over 70 influencers posting the brand each week ("Why fast-fashion brands are thriving on TikTok"). According to Forbes, over $60 \%$ of TikTok users are from Generation Z. Fashion brands have capitalized on this with heavy ads, sponsored content, dancing challenges, and even songs. One fashion brand that has capitalized heavily on TikTok's target demographic is Shein. Besides having their own TikTok account, Shein has relied heavily on sponsored content to promote their clothing. Celebrities like Hailey Bieber have even posted sponsored content for the brand. A major problem with Shein and other internet fashion brands is that they are usually online only. Besides the environmental impact of things like planes, ships, and trucks, the packaging of clothes further harms the environment. According to The Guardian, almost one-third of all solid waste in America comes from online shopping packaging. Besides just the packaging, online returns often end up in landfills due to them not being able to be resold. While these internet online fashion brands don't seem to be going anywhere, it is important for the consumer to be aware of where they are buying their clothes. These brands, like Shein and Pretty Little Thing, might have the latest trends for cheap prices and shipping, but their impact on the environment cannot be overlooked. As consumers we have to be mindful of the impact of these brands and try to avoid these fast fashion internet brands.

Student F discusses greenwashing in a similar context to Student D, briefly evaluating H\&M's website: “[H\&M makes] claims like "polyester content is recycled” with no evidence as to what that even means. These brands are doing good by being more environmentally aware and trying to end the cycle of fast fashion, but there still is a lot more that needs to be done in terms of slow fashion and sustainable lines." Also in a similar context of Student D, Student F uses only magazine articles as sources, relying primarily on statistics to bolster her argument. Student $\mathrm{F}$ offers a lot of her own analysis and interpretation of these issues, using the source's information as a catalyst for her own ideas.

Whie Student F did not make any drastic structural changes, there were additions made throughout the workshop process that bolstered her argument while offering opportunities for 
further analysis to be made in the final portfolio. Highlighted below is a quantitative measurement of Student F's level of understanding with writing and rhetoric:

\begin{tabular}{|c|c|c|}
\hline Beginner Level & Intermediate Level & Mastery Level \\
\hline $\begin{array}{l}\text { Students shows some } \\
\text { awareness of writing and } \\
\text { rhetorical strategies with few } \\
\text { misunderstanding/errors; } \\
\text { student has some } \\
\text { sophistication in sources used; } \\
\text { work has some structure, } \\
\text { needs more organization but } \\
\text { does not impede } \\
\text { understanding; work indicates } \\
\text { beginning level of } \\
\text { understanding rhetorical } \\
\text { strategies, student could } \\
\text { develop a deeper } \\
\text { understanding of rhetoric }\end{array}$ & $\begin{array}{l}\text { Students shows adequate } \\
\text { awareness of writing and } \\
\text { rhetorical strategies; student } \\
\text { has decent sophistication and } \\
\text { use of sources used; work has } \\
\text { mostly a logical structure and } \\
\text { organization; work indicates } \\
\text { average use and understanding } \\
\text { of rhetorical strategies }\end{array}$ & $\begin{array}{l}\text { Students shows strong } \\
\text { awareness of writing and } \\
\text { rhetorical strategies; student } \\
\text { has strong sophistication and } \\
\text { use of sources used; work has } \\
\text { logical structure; work has } \\
\text { effective use of rhetorical } \\
\text { strategies; student displays } \\
\text { strong understanding of } \\
\text { rhetoric throughout the project }\end{array}$ \\
\hline
\end{tabular}

While both students in this case study showcased an intermediate level of writing and rhetorical strategies within project 3 , both students showcased that structure, organization, and sources were used sufficiently and properly. Despite the difficulty of project 3, Student D and Student F credit workshop for allowing for better exploration of these difficult concepts and writing strategies. For example, Student D writes in her project 3 workshop reflection that "The workshop made me think about my voice by hearing what someone thought while reading my work... the workshops helped me understand the project better as a whole, through seeing the work that my peer had done, and develop my ideas, through hearing peer feedback." Similarly, Student F writes in her project 3 reflection that it "was really fun for me as fast fashion is something I am really interested in. I feel 
like I was able to use more of my own voice in my writing and make it somewhat personal as this is a topic I have researched a lot. The workshop helped my understanding of the project a lot as I was a little confused on the structure of the paper but my partner helped me figure it out." Both students found the workshop useful to their writing and rhetorical development and processes.

\section{Case Study 3: Student C, Student E, and Student G - Identity}

\section{Student $C$}

Student C is a first-year Business Administration major. Student C's first project was a song about ocean pollution; her second project was an interview with her mother about how environmentalism impacted her life as a mother, teacher, and woman; her third project was research on ocean pollution. Student $\mathrm{C}$ chose to revise projects 2 and 3 for the final portfolio.

Student $\mathrm{C}$ reflects thoughtfully on how the project enabled her own interests and choices with Project 1: "I chose my project based on my interests. I like writing music, and I'm fascinated in the ocean. I took a marine biology class in high school and learning about all the problems really grabbed my attention (and scared me) so I wanted to make my project center on one of those big issues. Because of this, I felt comfortable writing about the topic, and was interested in making it the best I could in the time frame." In the collective workshop reflection, Student C writes "All of my projects were on things that I was interested to learn more about. At my high school I never really got to write about things I was actually passionate about, so this was a super nice change because every project I had interest in! It has helped me realize what I like to write about the most too (so far). I did feel comfortable writing about these. In the research paper project, I was less comfortable for a little amount of time before I had finished my research because I didn't know 
about the specifics of some technologies and legislation for my issue. But as I read more, I grew more comfortable."

Something crucial to note that Student C pointed out is the difference in her writing from high school to her first semester of college. She notes that the projects allowed her to explore subjects that she was passionate about and interested in, encouraging an opportunity for her own voice, beliefs, and values to be validated in the process. Student $\mathrm{C}$ experimented with this voice in each project: creating, composing and performing a song in the style of Billie Eilish; reflecting on her own environmental impact and activism as a woman based on the interview with her mother; referencing her own interests and opinions throughout her research project. Highlighted below is a quantitative measurement of Student C's level of identity present in her work:

\begin{tabular}{|c|c|c|}
\hline Begi & Intermediate Level & Mastery Level \\
\hline $\begin{array}{l}\text { Student has began to develop a } \\
\text { "voice" in their writing yet } \\
\text { tries to write directly for the } \\
\text { instructor (not the audience of } \\
\text { project or for themselves); } \\
\text { student feels somewhat } \\
\text { comfortable to share their } \\
\text { beliefs/values/opinions in } \\
\text { writing yet shows hesitation in } \\
\text { expressing this; student } \\
\text { acknowledges in reflection } \\
\text { that workshop assisted in } \\
\text { developing their "identity" but } \\
\text { does not specify how; student } \\
\text { starts to include in their work } \\
\text { direct ties/interests to their } \\
\text { own personal identity (such as } \\
\text { gender, ethnicity, etc.); } \\
\text { student shows in their } \\
\text { reflection answers that they }\end{array}$ & $\begin{array}{l}\text { Student has developed a } \\
\text { "voice" in their writing; } \\
\text { student feels somewhat } \\
\text { comfortable to share their } \\
\text { beliefs/values/opinions in } \\
\text { writing; student acknowledges } \\
\text { in reflection that workshop } \\
\text { assisted in developing their } \\
\text { "identity"; student includes in } \\
\text { their work direct ties/interests } \\
\text { to their own personal identity } \\
\text { (such as gender, ethnicity, } \\
\text { etc.) occasionally; student } \\
\text { shows in their reflection } \\
\text { answers that they were } \\
\text { comfortable to discuss their } \\
\text { own beliefs/values and } \\
\text { included some } \\
\text { information/correlation to } \\
\text { their personal identity that, in }\end{array}$ & $\begin{array}{l}\text { Student has developed a } \\
\text { "voice" in their writing; } \\
\text { student feels comfortable to } \\
\text { share their } \\
\text { beliefs/values/opinions in } \\
\text { writing; student acknowledges } \\
\text { in reflection that workshop } \\
\text { assisted in developing their } \\
\text { "identity"; student includes in } \\
\text { their work direct ties/interests } \\
\text { to their own personal identity } \\
\text { (such as gender, ethnicity, } \\
\text { etc.); student shows in their } \\
\text { reflection answers that they } \\
\text { were comfortable and able to } \\
\text { include information regarding } \\
\text { their personal identity that, in } \\
\text { turn, allowed for development } \\
\text { of their individualized writer }\end{array}$ \\
\hline
\end{tabular}




\begin{tabular}{|l|l|l|}
\hline were somewhat comfortable & turn, allowed for development & identity \\
to discuss their own & of their individualized writer & \\
beliefs/values and included & identity & \\
some information/correlation & & \\
to their personal identity; & & \\
development of their & & \\
individualized writer identity & & \\
is in development but needs & & \\
more & & \\
\hline
\end{tabular}

In this sense, Student $\mathrm{C}$ emphasizes her identity as a student, woman, and environmentalist, which are undoubtedly showcased in her work but could be incorporated more so. Student C showcased a firm understanding of audience and incorporating personal attributes of writing, yet still seems hesitant in pushing herself beyond her comfort zone. Based on workshop observations of Student $\mathrm{C}$, she was extremely receptive to constructive criticism and was not afraid to explain her exigence or personal connections to the pieces. Shyness and hesitation was not necessarily a contributing factor within workshop observations between peers, yet hesitation to push herself further beyond writing on topics she was interested in was what earned Student C an intermediate level. In project 2, Student $\mathrm{C}$ seemed to explore more deeply her identity as a woman, yet these levels of exploration of identity were absent from the other two projects.

\section{Student E}

Student E is a first-year Political Science major. Student E's first project was a political cartoon about greenhouse gases; her second project was an interview with her brother about how his job affects his environmental impact and awareness; her third project was research on ecoracism. She chose to revise project 2 and 3 for the final portfolio. 
Student E writes similarly to Student C in her first workshop reflection: " I've never been assigned a project where the project itself was up to me. So it really allowed me to express myself along with my views. This project allowed me to incorporate my political views with environmental views. My own 'voice' shined because I was able to express myself freely." She continues to find how her own voice matters to the work she is completing in her project 3 workshop reflection: 'It made me feel like a 'spokesperson' on the issue of environmental racism. While we always advocate for coming up with solutions we fail to play our own roles in spreading awareness. I felt comfortable because I'm incredibly political which makes me naturally inclined to advocate for legislative reform, but I know it is much easier said than done."

In the collective workshop reflection, Student E writes “As for my authorial 'voice' it made me much more aware of the power we have through our words. We can advocate for change, spread awareness, and interpret other scholarly findings. My passion has always been politics and the United States government. I was definitely able to hone into my skillset to help strengthen my projects." Student E had consistently used her political science major as a catalyst for the type of work she explored and produced in this course. Highlighted below is a quantitative measurement of Student E's level of identity present in her work:

\begin{tabular}{|c|c|c|}
\hline Beginner Level & Intermediate Level & Mastery Level \\
\hline $\begin{array}{l}\text { Student has began to develop a } \\
\text { "voice" in their writing yet } \\
\text { tries to write directly for the } \\
\text { instructor (not the audience of } \\
\text { project or for themselves); } \\
\text { student feels somewhat } \\
\text { comfortable to share their } \\
\text { beliefs/values/opinions in }\end{array}$ & $\begin{array}{l}\text { Student has developed a } \\
\text { "voice" in their writing; } \\
\text { student feels somewhat } \\
\text { comfortable to share their } \\
\text { beliefs/values/opinions in } \\
\text { writing; student acknowledges } \\
\text { in reflection that workshop } \\
\text { assisted in developing their }\end{array}$ & $\begin{array}{l}\text { Student has developed a } \\
\text { "voice" in their writing; } \\
\text { student feels comfortable to } \\
\text { share their } \\
\text { beliefs/values/opinions in } \\
\text { writing; student acknowledges } \\
\text { in reflection that workshop } \\
\text { assisted in developing their }\end{array}$ \\
\hline
\end{tabular}




\begin{tabular}{|c|c|c|}
\hline $\begin{array}{l}\text { writing yet shows hesitation in } \\
\text { expressing this; student } \\
\text { acknowledges in reflection } \\
\text { that workshop assisted in } \\
\text { developing their "identity" but } \\
\text { does not specify how; student } \\
\text { starts to include in their work } \\
\text { direct ties/interests to their } \\
\text { own personal identity (such as } \\
\text { gender, ethnicity, etc.); } \\
\text { student shows in their } \\
\text { reflection answers that they } \\
\text { were somewhat comfortable } \\
\text { to discuss their own } \\
\text { beliefs/values and included } \\
\text { some information/correlation } \\
\text { to their personal identity; } \\
\text { development of their } \\
\text { individualized writer identity } \\
\text { is in development but needs } \\
\text { more }\end{array}$ & $\begin{array}{l}\text { "identity"; student includes in } \\
\text { their work direct ties/interests } \\
\text { to their own personal identity } \\
\text { (such as gender, ethnicity, } \\
\text { etc.) occasionally; student } \\
\text { shows in their reflection } \\
\text { answers that they were } \\
\text { comfortable to discuss their } \\
\text { own beliefs/values and } \\
\text { included some } \\
\text { information/correlation to } \\
\text { their personal identity that, in } \\
\text { turn, allowed for development } \\
\text { of their individualized writer } \\
\text { identity }\end{array}$ & $\begin{array}{l}\text { "identity"; student includes in } \\
\text { their work direct ties/interests } \\
\text { to their own personal identity } \\
\text { (such as gender, ethnicity, } \\
\text { etc.); student shows in their } \\
\text { reflection answers that they } \\
\text { were comfortable and able to } \\
\text { include information regarding } \\
\text { their personal identity that, in } \\
\text { turn, allowed for development } \\
\text { of their individualized writer } \\
\text { identity }\end{array}$ \\
\hline
\end{tabular}

Similarly to Student C, Student E relied on her identity as a student rather than emphasize any other aspects of her personal identity. Student E shows more reflective thought regarding how the projects workshopped affected her own personal interest and choices, yet similarly to Student C, there seems to be a sense of hesitation to explore this more deeply in writing.

\section{Student $G$}

Student G is a fourth-year Physics major. Student G's first project was a collection of poems about the California wildfires; her second project was an interview with her roommate about vegetarianism and animal activism; her third project was research on plastic recycling and the company BioCellection. Student G chose to revise project 1 and 3 for the final portfolio. 
Student G writes in her first project reflection that she "definitely did have the interest in this project as I am living in the effects of the California wildfires. I do think I have a better idea of my author voice, I do enjoy using diction and some visual rhetoric to help my ideas grow." Likewise, with her second project encouraged her to "think more critically about my own involvement in environmentalism and how effective or noneffective it has been. I was pretty interested in learning a little bit more about my interviewees ideas about vegetarianism. I felt comfortable asking and writing the project." As self-stated within her collective workshop reflection, "I really enjoyed all the pieces because I wanted to do them. I think the second project was my least favorite because it was not that interesting to me to interview someone I kinda knew most everything about." The third project seemed to spark the most interest relevant to her major, as she self-reports in her third project reflection "I was super interested in this topic before researching so the research and even the writing(which i rarely enjoy) were extremely enjoyable." Highlighted below is a quantitative measurement of Student G's level of identity present in her work:

\begin{tabular}{|c|c|c|}
\hline Beginner Level & Intermediate Level & Mastery Level \\
\hline $\begin{array}{l}\text { Student has began to develop a } \\
\text { "voice" in their writing yet } \\
\text { tries to write directly for the } \\
\text { instructor (not the audience of } \\
\text { project or for themselves); } \\
\text { student feels somewhat } \\
\text { comfortable to share their } \\
\text { beliefs/values/opinions in } \\
\text { writing yet shows hesitation in } \\
\text { expressing this; student } \\
\text { acknowledges in reflection } \\
\text { that workshop assisted in } \\
\text { developing their "identity" but }\end{array}$ & $\begin{array}{l}\text { Student has developed a } \\
\text { "voice" in their writing; } \\
\text { student feels somewhat } \\
\text { comfortable to share their } \\
\text { beliefs/values/opinions in } \\
\text { writing; student acknowledges } \\
\text { in reflection that workshop } \\
\text { assisted in developing their } \\
\text { "identity"; student includes in } \\
\text { their work direct ties/interests } \\
\text { to their own personal identity } \\
\text { (such as gender, ethnicity, } \\
\text { etc.) occasionally; student }\end{array}$ & $\begin{array}{l}\text { Student has developed a } \\
\text { "voice" in their writing; } \\
\text { student feels comfortable to } \\
\text { share their } \\
\text { beliefs/values/opinions in } \\
\text { writing; student acknowledges } \\
\text { in reflection that workshop } \\
\text { assisted in developing their } \\
\text { "identity"; student includes in } \\
\text { their work direct ties/interests } \\
\text { to their own personal identity } \\
\text { (such as gender, ethnicity, } \\
\text { etc.); student shows in their }\end{array}$ \\
\hline
\end{tabular}




\begin{tabular}{|c|c|c|}
\hline $\begin{array}{l}\text { does not specify how; student } \\
\text { starts to include in their work } \\
\text { direct ties/interests to their } \\
\text { own personal identity (such as } \\
\text { gender, ethnicity, etc.); } \\
\text { student shows in their } \\
\text { reflection answers that they } \\
\text { were somewhat comfortable } \\
\text { to discuss their own } \\
\text { beliefs/values and included } \\
\text { some information/correlation } \\
\text { to their personal identity; } \\
\text { development of their } \\
\text { individualized writer identity } \\
\text { is in development but needs } \\
\text { more }\end{array}$ & $\begin{array}{l}\text { shows in their reflection } \\
\text { answers that they were } \\
\text { comfortable to discuss their } \\
\text { own beliefs/values and } \\
\text { included some } \\
\text { information/correlation to } \\
\text { their personal identity that, in } \\
\text { turn, allowed for development } \\
\text { of their individualized writer } \\
\text { identity }\end{array}$ & $\begin{array}{l}\text { reflection answers that they } \\
\text { were comfortable and able to } \\
\text { include information regarding } \\
\text { their personal identity that, in } \\
\text { turn, allowed for development } \\
\text { of their individualized writer } \\
\text { identity }\end{array}$ \\
\hline
\end{tabular}

Student G minimally explores her own identity within both the workshop reflections and within the projects. While she recognizes that the projects she created each stemmed from her own interests and choices, very little effort to include her own personal identity was made. Like the others, Student $\mathrm{G}$ had a firm understanding of audience and developing a voice dependent on the audience. Unlike the others, Student G fails to recognize in her reflections how these levels of personal interest, choices, and connections to her identity-even as a student-were relevant. While Student G openly verbally expressed her opinions and concerns when observed in workshop and when in individual conferences with me, yet these opinions were disregarded when in the written or composed form.

Students $\mathrm{C}, \mathrm{E}$, and $\mathrm{G}$ all relied to some extent on their identities as students, limiting themselves the opportunity to explore more personal facets of themselves within their writing. Why are the students hesitant to explore more personal facets of their identities? Is it because high 
school and previous writing assignments so often excluded these facets of inclusion? Is it because they only see themselves as a student when in an academic setting - thereby limited to the confines of exploring student-centered identity? Is it because of online learning? Why are students more open to voicing their opinions and connections to the work verbally rather than incorporate it into their writing? Is it because they feel they can openly discuss these connections with their peers, yet do not expect me to want them to incorporate these connections? Is that a product of past school experience? These questions, although difficult to answer, will be questions I aim to receive answers on in our interview and in next semester's study.

\section{Collective Analysis: Metacognition of Process}

Below are excerpts from the participants' workshop reflections that indicate metacognition of process. The following are excerpts from each participant:

- "This workshop has helped me a lot with my authorial 'voice'. The writing style of this project was not the style I am used to so I had to step out of my comfort zone a lot. This has made me a lot more comfortable with writing profiles as I now know how they are supposed to sound, what should go in them. Etc."

- "It was incredible to see the project go from an idea to a full scale project within a few days. The 3 day process made the whole thing much less overwhelming by taking it step by step."

- "[Workshop] made me realize that my words can truly make someone ponder their own lives. It felt weird being the interview conductor and not the one being interviewed. As a student, we're used to receiving questions and having to answer them, but this project reversed that. I felt comfortable interviewing about this topic because it was my brother. 
Has [sic] it been a stranger it would've felt weird having to conduct a Rough Draft 1 prior to the official interview."

- "[Workshop] taught me how to apply rhetoric verbally. Usually, im used to implementing it in my writing. Rhetoric effectiveness is so broad and can be used in multiple different works (even interviews)."

- "Workshop as a whole has helped me to not only consider my own application of rhetoric and the choices I make, but to consider how they will be received and perceived to an outside individual (possibly a consumer of my writing). I have also found that I understand academic writing in connection with rhetoric and audience in a much deeper manner now."

- "I think the idea document sounded pretty dumb to me at first but it helps so much to really consider what you TRULY felt passionate about writing about and were able to consider if it would be doable....I really think the workshops worked well with this class and the structure was great.”

- "One of the rhetorical strategies that I found myself using frequently in my work was an appeal to logic and appeal to emotion. These devices seemed to fit with the topic of Environmentalism quite often and contextually made sense for many different audiences of environmental work. One thing I learned from using these techniques often was how to alter them to fit different tones and writing styles. I used them in more casual text post writing and also in more academic research-style work as well depending on the assignment." 
- "All of our workshops made a significant difference in the way I approach writing. Using this many steps including idea doc, detailed outline and 2 rough drafts really highlights the importance of planning out your writing to ensure its effectiveness."

- "The workshop setup/schedule definitely contributed to my confidence in the writing I produced and helped me to better plan out my work which has helped my overall writing improve. I had a tendency to avoid making outlines and plan out my work and just dive in instead which wasn't the best plan for every assignment, but seeing how beneficial making the detailed outlines and even the idea documents and how that has improved my overall work and the structure is one big takeaway I will have from workshop."

- "I think the most beneficial part of the workshop process for me was getting specific feedback from my partner about my ideas, organization, rhetoric, and more. It was also beneficial to look at and give feedback to my peer's work as it would help me reflect on my own work and use that same critical lens to look at my own paper."

- "I really enjoyed workshop! I learned techniques like the importance of peer feedback and was able to practice many rhetorical devices that I wished to implement. Workshop was very helpful for me!"

Students were able to articulate not only the effectiveness of the workshop process as a whole but also referenced specific projects and how they shaped their writing and rhetoric strategies and levels of understanding. It seems most students learned ways of planning and strategizing their writing, reflecting on how the workshop process affected other areas of their learning and writing processes.

As mentioned above, most students either reflected briefly or extensively in the workshop reflections regarding the workshop process. Some students exemplified a metacognitive awareness 
more than others, with some participants implying an opportunity for learning transfer due to workshop, stating "all of our workshops made a significant difference in the way I approach writing" or that they "understand academic writing in connection with rhetoric and audience in a much deeper manner now." Student B stated "I had a tendency to avoid making outlines and plan out my work and just dive in instead which wasn't the best plan for every assignment, but seeing how beneficial making the detailed outlines and even the idea documents and how that has improved my overall work and the structure is one big takeaway I will have from workshop." Based on the workshop reflection answers, participants indicate a possibility for writing and rhetorical approaches to transfer beyond the scope of the course. While learning transfer is not the intended goal, I would like to investigate whether this does occur in the next phase of the study. Highlighted below are the collective quantitative measures of metacognitive awareness for the participants based on the quotes above:

\begin{tabular}{|c|c|c|}
\hline Beginner Level & Intermediate Level & Mastery Level \\
\hline $\begin{array}{l}\text { Student has shown some } \\
\text { understanding of the benefits } \\
\text { of process to their work and } \\
\text { acknowledges the workshop } \\
\text { has helped them, their identity, } \\
\text { and/or their growth as a writer; } \\
\text { student begins to identify the } \\
\text { writing/rhetorical choices } \\
\text { made in their work but does } \\
\text { not make deeper connections } \\
\text { to the significance of making } \\
\text { these choices; student briefly } \\
\text { reflects on these choices and } \\
\text { how they affected their work; } \\
\text { students uses reflection } \\
\text { activities begin to understand } \\
\text { their writing/rhetoric choices }\end{array}$ & $\begin{array}{l}\text { Student has shown a decent } \\
\text { understanding of the benefits } \\
\text { of process to their work, their } \\
\text { identity, and/or their growth as } \\
\text { a writer; student can identify } \\
\text { the significance of their } \\
\text { writing/rhetorical choices; } \\
\text { student reflects on these } \\
\text { choices in the reflection } \\
\text { activity and somewhat } \\
\text { emphasizes how these choices } \\
\text { affected their work; students } \\
\text { uses reflection activities to } \\
\text { better understand their } \\
\text { writing/rhetoric choices and } \\
\text { begins to showcase a thought } \\
\text { process in terms of how these }\end{array}$ & $\begin{array}{l}\text { Student has shown a firm } \\
\text { understanding of the benefits } \\
\text { of process to their work, their } \\
\text { identity, and/or their growth as } \\
\text { a writer; student can identify } \\
\text { the significance of their } \\
\text { writing/rhetorical choices; } \\
\text { student reflects on these } \\
\text { choices and how they affected } \\
\text { their work; students uses } \\
\text { reflection activities to dissect, } \\
\text { discern, and understand their } \\
\text { writing/rhetoric choices and } \\
\text { how it applies to their work } \\
\text { and to them }\end{array}$ \\
\hline
\end{tabular}


and can identify how it applies to their work but can use more development and deeper analysis in how these choices relate to them as a writer choices apply to their work but can be developed deeper in terms of how these choices relate to them as a writer

While each participant did not extensively reflect the workshop process and how this affected their writing process, each participant was able to convey to some degree how workshop affected them. As a collective whole, the quantitative intermediate level deems relevant given some students were able to express how this process changed them more deeply than others. Are some students more prone to honestly expressing themselves than others? Did some students not reflect as heavily as others because it did not matter to them as much? Regardless, each participant seemed to learn something from the workshop process, some were simply more capable at expressing that than others.

\section{Collective Analysis: Confidence/Growth in Writing}

Below are excerpts from the participants' workshop reflections that indicate confidence and growth in writing. The following are excerpts from each participant:

- "I would feel very confident in using some of these strategies in the future. I think learning these strategies opens your eyes to how companies, writers and groups use rhetoric. In addition, learning these rhetorical devices in the first project will be beneficial to future works in this class."

- "The workshop process has significantly improved my confidence in my writing, since me and my partner were able to be transparent with each other in regards to what was 
good and what needed work. Yes, I am positive my writing has improved since the beginning of the semester."

- "I feel quite confident in my ability to use these devices again in the future. After applying them in this project I feel that I have gained a deeper understanding of what is efficient in getting across a message. I also think that the workshop (explaining my rhetoric to a partner) helped me develop my understandings of these concepts which makes me more confident."

- "Hearing reinforcement from my peers did make me more confident, if not fully in my writing then in my ideas. I do see improvement in my writing from the beginning of the semester to now."

- "[I feel] extremely confident. It helped further my knowledge of rhetoric and how to apply it in different ways to convey different meanings. It taught me that changing one little thing can change the whole overall meaning completely."

- "Yes, my writing definitely improved since the start of the semester. Going back to high school, my teacher didn't really motivate me, in fact he mostly just brought me down. I was able to pick myself back up, start fresh, and combine my environmental science knowledge with my writing skills. While I'm no rhetorical genius yet, my understanding has increased since my discussion leadership which was the first presentation of the class. The workshop process helped by receiving immediate feedback each class. It helped make class time more productive."

- "The 3 day set up made me much more confident in my writing as I was able to get feedback right away on what I was turning/planning on doing. I feel like my writing has improved a lot as I learned how to better narrow down ideas." 
- "I feel that I was able to write the essays better because I had more time to consider my work and what needed to be changed. I think my writing has improved a lot but I have also learned that I need to ask people to help me with pieces because it does really help."

Students were able to showcase the ways in which they have grown more confident and how workshop has helped in increasing their confidence. Likewise, students implied an opportunity for learning transfer in conjunction with their confidence and growth in writing, stating "I would feel very confident in using some of these strategies in the future." Similarly to the metacognitive reflection answers, these reflection answers indicate an ability for transfer to be possible beyond the scope of the course, potentially transferring to other courses or writing approaches. While learning transfer cannot be measured at this stage of the study in terms of transfer to other courses or forms of writing, it appears that this workshop process inspired a strengthened understanding of writing and rhetorical strategies that can be implemented in future endeavors. Each of the seven participants stated that they have grown confident in their writing and rhetoric skills and processes. Highlighted below are the collective quantitative measures of confidence and growth based on the participants' quotes above:

\begin{tabular}{|c|c|c|}
\hline Beginner Level & Intermediate Level & Mastery Level \\
\hline $\begin{array}{l}\text { Student suggests they have } \\
\text { had increased confidence in } \\
\text { writing through reflections yet } \\
\text { does not state this directly; } \\
\text { student displays some } \\
\text { metacognitive awareness of } \\
\text { writing choices in the } \\
\text { reflections; student is able to } \\
\text { recognize their growth as a } \\
\text { writer throughout the semester }\end{array}$ & $\begin{array}{l}\text { Student implies they have had } \\
\text { increased confidence in } \\
\text { writing through reflections; } \\
\text { student displays decent } \\
\text { metacognitive awareness of } \\
\text { writing choices in the } \\
\text { reflections; student is able to } \\
\text { recognize and articulate their } \\
\text { growth as a writer throughout } \\
\text { the semester; student shows }\end{array}$ & $\begin{array}{l}\text { Student directly states they } \\
\text { have had increased confidence } \\
\text { in writing through reflections; } \\
\text { student displays } \\
\text { metacognitive awareness of } \\
\text { writing choices in the } \\
\text { reflections; student is able to } \\
\text { recognize and articulate their } \\
\text { growth as a writer throughout } \\
\text { the semester; student shows }\end{array}$ \\
\hline
\end{tabular}




\begin{tabular}{|c|c|c|}
\hline $\begin{array}{l}\text { but articulates this growth } \\
\text { minimally (not offering much } \\
\text { metacognition on their } \\
\text { process); student shows some } \\
\text { confidence in their writing } \\
\text { choices, assertion of } \\
\text { opinion/points, discourse in } \\
\text { the community yet } \\
\text { voices/shows their hesitance } \\
\text { in fully embracing their } \\
\text { interests/beliefs/values in their } \\
\text { writing; some revisions made } \\
\text { to work throughout workshop } \\
\text { process show strong } \\
\text { development of understanding } \\
\text { and benefit the work and } \\
\text { improved understanding of the } \\
\text { prompt }\end{array}$ & $\begin{array}{l}\text { confidence in their writing } \\
\text { choices, assertion of } \\
\text { opinion/points, discourse in } \\
\text { the community yet shows } \\
\text { some hesitance in fully } \\
\text { embracing their } \\
\text { interests/beliefs/values in their } \\
\text { writing; revisions made to } \\
\text { work throughout workshop } \\
\text { process show decent } \\
\text { development and } \\
\text { understanding; student shows } \\
\text { an understanding of the } \\
\text { prompt and revisions made } \\
\text { were related to the prompt and } \\
\text { did not diminish } \\
\text { understanding of the work }\end{array}$ & $\begin{array}{l}\text { increased confidence in their } \\
\text { writing choices, assertion of } \\
\text { opinion/points, discourse in } \\
\text { the community; shows } \\
\text { comfort in discussing their } \\
\text { interests/beliefs/values in their } \\
\text { writing; revisions made to } \\
\text { work throughout workshop } \\
\text { process show strong } \\
\text { development of understanding } \\
\text { and benefit the work; student } \\
\text { shows firm understanding of } \\
\text { the prompt and revisions made } \\
\text { were cohesive to the prompt }\end{array}$ \\
\hline
\end{tabular}

This category seems to be the most consistent among all participants, with each making revisions that enhanced the project and explicitly stating they have increased levels of confidence and have experienced some level of growth in their writing. Like with metacognition, some students are able to reflect and articulate this concept more deeply than others. This category was the only category that was consistently upheld among all participants. All participants seemed to grow more comfortable with writing and rhetoric as the semester naturally progressed, building their project topics off of previously explored topics earlier in the semester and finding ways to include their own interests in the process. Yet, I still question how can I have my students more explicitly showcase and reflect this confidence and growth in writing?

Collective Analysis: Workshop 
Below is a table for the number of answers from the seven participants across the three project workshop reflections for the following two questions:

What day of the workshop was most helpful to you in terms of receiving peer feedback?

\begin{tabular}{|l|l|l|}
\hline Idea Document & Detailed Outline & Rough Draft 1 \\
\hline 5 & 10 & 7 \\
\hline
\end{tabular}

What day of workshop was most helpful to you in terms of the workshop material ("Idea Document," "Detailed Outline," "Rough Draft 1")? What material helped you think the most thoroughly about your ideas, plans, and writing? Why?

\begin{tabular}{|l|l|l|}
\hline Idea Document & Detailed Outline & Rough Draft 1 \\
\hline 0 & 16 & 7 \\
\hline
\end{tabular}

Based on the responses above, the Detailed Outline material proved most beneficial for students, and when referring back to the workshop reflections, most students claimed the Detailed Outline offered enough detail about the project while still offering opportunity for open conversation and drastic revision. In terms of the use and effectiveness of the workshop, below are excerpts from all participants regarding workshop: 
- "Providing general feedback from the peer reviewer allowed me to think more thoroughly about my work. A lot of the times [sic] it wasn't drastic changes that I should be making, but rather a few quick changes that significantly effect the purpose of the work. In addition, when analyzing my peers work, I was able to learn a few things that I could incorporate into my work."

- "The workshop as a whole opened my mind to new ideas and rhetorical strategies I could incorporate in my work. Having somebody to look at your work other than yourself allowed me to make changes in my work that I didn't notice previously."

- "[In workshop] I feel I can informally introduce my topic to someone who hasn't been as focused on it as I have and get some unbiased feedback which has been really helpful. I also think that this helps me, even with just reading aloud and explaining my topic, to identify parts that I need to change/edit."

- "The workshops as a whole allowed for me to better understand the requirements. By seeing my peers work, I was able to determine if I was on the right track in terms of length, detail, and competition [sic (completion)]. If any directions were unclear or I misheard, the workshops as a whole cleared all my confusion."

- "The most beneficial part of the workshop process was being able to talk with another person about my ideas so I could figure them out better myself, and get feedback on any ideas of what I could change or fix. It was helpful to hear about stylistic changes I could make, what rhetoric I could include, and what ideas were liked a lot."

- "My partner was super helpful in answering my questions and adding interesting perspectives. I tend to overlook small things because I get so caught up on the big picture. [My partner] helped me remember the little things" 
- "The workshop process helped me see some of my peers work and discuss the projects with a partner. This was helpful to get a glimpse of what others were doing and build off of some of their ideas too, applying some of the critiques I had for their projects to my own work as well. Receiving feedback also helped a ton with determining how to effectively use rhetorical devices, my organization, and more."

- "The workshops helped me understand the project better as a whole through seeing the work that my peer had done, and develop my ideas and rhetorical strategies through hearing peer feedback."

- "Everything about workshop was extremely useful and by breaking it up in different stages makes it less overwhelming."

- "The workshops helped my understanding of the projects a lot s [sic] I was able to ask my partner any questions right away. We also bounced any concerns off of each other and this helped me gain a new perspective or thought I didn't have before."

- "My peers were all very uplifting in each workshop. It was also good to get the constructive feedback too."

Not only were the students fond of the workshop structure and being able to collaboratively work with one another, my observations of their workshop proved this further: each participant I observed was precise in their explanation of feedback, offering helpful and respectful constructive criticism, and discussed their partner's work with great care. In all of my observations, the participants were quite cordial with one another, laughing and establishing bonds of friendship even over a distanced Zoom call. Each participant was complimentary, kind, and engaged while still taking the workshop process seriously and honestly. Highlighted below are the collective quantitative measures of workshop based on the quotes above: 


\begin{tabular}{|c|c|c|}
\hline Beginner Level & Intermediate Level & Mastery Level \\
\hline $\begin{array}{l}\text { Student was sometimes } \\
\text { engaging with others and } \\
\text { collaboratively discussing } \\
\text { their work in the Zoom } \\
\text { workshops; student shows } \\
\text { some levels of engagement } \\
\text { with the prompt; student gave } \\
\text { some helpful feedback to } \\
\text { peers during asynchronous } \\
\text { workshop; student reflection } \\
\text { indicates workshop feedback } \\
\text { was helpful/was sometimes } \\
\text { helpful; student work } \\
\text { indicates some changes were } \\
\text { made based on feedback } \\
\text { given; some changes made to } \\
\text { work were mostly beneficial } \\
\text { to make with some } \\
\text { redundancies }\end{array}$ & $\begin{array}{l}\text { Student was mostly engaging } \\
\text { with others and } \\
\text { collaboratively discussing } \\
\text { their work in the Zoom } \\
\text { workshops; student shows } \\
\text { decent levels of engagement } \\
\text { with the prompt; student gave } \\
\text { mostly helpful feedback to } \\
\text { peers during asynchronous } \\
\text { workshop; student reflection } \\
\text { indicates workshop feedback } \\
\text { was helpful and constructive; } \\
\text { student work indicates some } \\
\text { changes were made based on } \\
\text { feedback given; changes made } \\
\text { to work were mostly } \\
\text { beneficial to make with some } \\
\text { redundancies }\end{array}$ & $\begin{array}{l}\text { Student was engaging with } \\
\text { others and collaboratively } \\
\text { discussing their work in the } \\
\text { Zoom workshops; student } \\
\text { shows stronger levels of } \\
\text { engagement with the prompt; } \\
\text { student gave helpful feedback } \\
\text { to peers during asynchronous } \\
\text { workshop; student reflection } \\
\text { indicates workshop feedback } \\
\text { was helpful and constructive; } \\
\text { student work indicates } \\
\text { changes were made based on } \\
\text { feedback given; changes made } \\
\text { to work were beneficial and } \\
\text { relevant to make }\end{array}$ \\
\hline
\end{tabular}

All participants showcased in observations and voiced in their reflections that the workshop was helpful in many regards. If anything comes out of this study, it should be the recognition that collaborative learning and workshops are essential to individual and communal student learning development-especially in online learning. Given the circumstances with COVID-19, establishing communal identity was crucial due to the distanced nature of Zoom, as bonds and friendships between students were established through Zoom workshop breakout rooms. As indicated in the quotes above, students found it helpful to talk things through with their partners; as Student D stated: "The workshops helped me because I was able to talk through some of my ideas with another person. It was helpful to both hear from another perspective and better walk 
through my own thoughts." The participants found it helpful to make changes, and the majority of them took their partner's advice to heart. Likewise, the feedback the participants gave during workshop observations were beneficial to the partner's work as a whole, showcasing the students are aware of what types of changes strengthen and weaken a piece while still being mindful and respectful of their partner while giving these suggestions. When considering my workshop observations, each participant was continuously offering constructive feedback in a friendly and respectful manner. While conversation would become joking or laughing, it was clear that bonds had been made as students began to share information with their partners about their majors, writing choices, and inspirations behind the projects. I observed twice in workshop some participants offering their contact information as a way to be of more help outside of class, which indicates a sense of communal bonding through this distancing platform. Not only was it evident and self-reported in the reflections that students learned about writing and rhetoric within the workshop, but they learned how to communicate effectively and meaningfully, establishing personal and developmental growth in the process. Online learning may have bolstered the ability to establish communal identities and bonds among the students, yet this reiterates the importance of allowing for a space of communal identities, bonding, and strategizing to emerge regardless of online or in-person instruction.

\section{Limitations}

A limitation that became a concern for me when analyzing my data was the use of rubrics. I feared that my creation and implementation of a quantitative measure of the effectiveness would defeat the purpose of the students' reflection answers, almost overriding it in a sense. I acknowledge that the rubrics have a narrow scope within the wider realm of coursework analysis, yet my use of these rubrics were not to "judge" their writing as perfect nor as even being possible 
to be measured on such a narrow scale. The rubrics were designed to be a method of analysis in terms of threshold concepts and how the students are meeting these threshold concepts within their project and reflection writing. The quantitative measures mentioned throughout the results portion are by no means definitive, exact, nor perfect. Each student involved in this study grew significantly as a writer, rhetorician, student, and human throughout the semester; a rubric cannot determine and represent this multifaceted growth holistically. If I were to do this study over, I would implement surveys rather than rubrics, incorporating yes/no answers and opportunities for expansion of short answers on their yes/no choice in order to avoid the potential issues and concerns that can arise with using rubrics and this mode of quantitative measurement.

Although unavoidable, another limitation was switching the workshop structure to accommodate online learning due to COVID-19. I had to quickly rework how workshop was originally designed, creating written peer feedback to be completed prior to workshop rather than verbal feedback given during workshop. While this did serve useful for students to refer back to, I fear it added more work onto their already hectic schedules, making workshop more daunting than it was ever intended to be. Likewise, COVID-19 created earlier "burn out" or "fatigue" for my students given the excessive Zoom calls and work for other courses. However, my students continuously put great care and effort into their written and verbal feedback, creating a meaningful and rewarding experience despite the circumstances. 